\title{
Computational Drug Repurposing Resources and Approaches for Discovering Novel Antifungal Drugs against Candida albicans N-Myristoyl Transferase
}

\author{
Afzal Hussain* (D) and Chandan Kumar Verma \\ Department of Bioinformatics, Maulana Azad National Institute of Technology, Bhopal - 462 003, \\ Madhya Pradesh, India.
}

\begin{abstract}
Candida albicans is a yeast that is an opportunistic fungal pathogen and also identified as ubiquitous polymorphic species that is mainly linked with major fungal infections in humans, particularly in the immunocompromised patients including transplant recipients, chemotherapy patients, HIV-infected patients as well as in low-birth-weight infants. Systemic Candida infections have a high mortality rate of around 29 to $76 \%$. For reducing its infection, limited drugs are existing such as caspofungin, fluconazole, terbinafine, and amphotericin B, etc. which contain unlikable side effects and also toxic. This review intends to utilize advanced bioinformatics technologies such as Molecular docking, Scaffold hopping, Virtual screening, Pharmacophore modeling, Molecular dynamics (MD) simulation for the development of potentially new drug candidates with a drug-repurpose approach against Candida albicans within a limited time frame and also cost reductive.
\end{abstract}

Keywords: Benzofurans, Benzothiazoles, Biofilm, Inhibitors, Myristoylation, Simulation

C The Author(s) 2021. Open Access. This article is distributed under the terms of the Creative Commons Attribution 4.0 International License which permits unrestricted use, sharing, distribution, and reproduction in any medium, provided you give appropriate credit to the original author(s) and the source, provide a link to the Creative Commons license, and indicate if changes were made. 


\section{INTRODUCTION}

Invasive infections caused by fungal pathogens are life threatening opportunistic infections, having a high rate of mortality and morbidity in patients. It infects billions of individuals and is responsible for 1.5-2 million deaths annually ${ }^{1-4}$. Fungal infections have risen dramatically in patients over the last decades which are immunocompromised, because of cancer chemotherapy, solid and hematologic organ transplantation, broad use of antibiotics, surgery, and long-term use of corticosteroids ${ }^{5}$. Invasive fungal infections are particularly exposed to patients receiving cancer treatment, transplant recipients, intensive care unit (ICU) care, and also with acquired immune deficiency syndrome (AIDS). The immunocompromised hosts are having a great risk of these infections with mortality rates from $20 \%$ to $40 \%$ and it continues to be high, which is relied on what kind of infecting fungal species and the clinical treatment. Several fungal species are present in the world; however, some species, including Candida, Cryptococcus, as well as Aspergillus, lead to life threatening infection in more than $90 \%$ of the population. One species of fungus well known as Candida albicans, an ascomycete, and a polymorphic fungus. It is capable of reversibly transforming to various morphologies, include (1) yeast forms, (2) pseudohyphae forms, and (3) true hyphae forms. It's both commensal as well as opportunistic pathogen among humans and ranks as the fourth most common threat of nosocomial bloodstream infections in modern hospitals with roughly $40 \%$ death rates ${ }^{3,6-17}$. Pathogenicity of invasive infection caused by Candida albicans is regulated by several factors namely invasive (a) filamentation, (b) biofilm development, and (c) the ability to escape from the immune system ${ }^{18}$. Studies of metabolic labeling state that Candida albicans synthesize protein $\mathrm{N}$-myristoyl (20-kDa). Myristoyl-CoA: N-myristoyl transferase (NMT), was reported as a target for antifungal as well as antiviral treatment ${ }^{19}$. Antifungal drugs may be used to handle such infections; however, the mortality rates remain high around $50 \%$ and there was also a high prevalence of Invasive fungal infections. Discussing treatment options, Antifungals Azoles, echinocandins, and polyenes are existing for the curing of fungal infections which are limited and clinically available ${ }^{18}$. Azoles and polyenes target different biological fungal processes relevant to ergosterol metabolism as well as echinocandins targets cell wall $\beta-1,3$ glucan production. 5-flurocytosine is usually used as adjunctive therapy. Fazly et al. described filastatin (a small molecule) that prevents filamentation, adhesion, and virulence of Candida albicans ${ }^{20}$. Garcia et al. reported (N1-(3,5-dichlorophenyl)-5-chloro-2 hydroxybenzamide) halogenated salicylanilide and its analogs Niclosamide, an antifilament molecules that inhibited Candida albicans' biofilm development and had similar antibiofilm and antifilamentation activities ${ }^{21}$. Siwek et al. investigated the antifungal effect of 4-arylthiosemicarbazides and found the isoquinoline-thiosemicarbazide compound to exhibit greater affinity compared to the native ligand ${ }^{22}$. These antifungal agents have significant clinical failures such as unfavorable pharmacokinetic profiles, restricted antifungal range, significant side effects, minimal clinical effectiveness, drug-drug interactions, as well as increased drug-resistance. Therefore it is an urgent need to use all the advanced Bioinformatics tools and techniques to improve the existing fungal drugs or designing novel drugs against it. Existing drugs and the same structural analogous shows the resistant problem on the antifungal targets. Therefore, searching out the new inhibitor is the most promising approach to tackle the resistant fungal infections ${ }^{23-35}$

This review is the effort to use advanced bioinformatics techniques such as Molecular docking, Scaffold hopping, Virtual screening, Pharmacophore modeling, Molecular simulation for developing novel drug candidates with drug repurposing approach against Candida albicans within a short period, cost-reducing and solve the resistant problem in fungal infections.

\section{Candida Albicans: Biofilm Formation}

Earlier, microbiologists have studied planktonic cells which are free-floating cells in pure culture. Later they have discovered that there is a link available between sessile cells, microbial pathogenesis, and infections associated with humans and it differs basically from a planktonic cell present in the same species ${ }^{36}$. A broad variety of fungi alternately connecting planktonic 
cells (freely suspended cells) and multicellular populations, known as biofilms ${ }^{37}$. Biofilms are characterized as well-structured microorganism populations that are interconnected with the surface as well as enclosed by an extracellular matrix (ECM) produced by themselves ${ }^{38}$. The biofilms-associated microorganism is related with several human diseases such as cystic fibrosis, native valve endocarditis and to colonize an extensive range of medical devices which taking into consideration that these structures are very much associated with antimicrobial-resistant and it is very difficult to manage such kind of infections within the clinical setting ${ }^{39}$. A short time ago it has been understood that fungal species form biofilms and it is associated with the escalating clinical problem ${ }^{38,40,41}$. So many Candida Species have been identified but the most famous studied species is Candida albicans as a well-developed biofilm activity with the most adaptable opportunistic pathogen ${ }^{42}$. There have been so many Candida species reported, but as a well-developed biofilm operation with the most adaptable opportunistic pathogen, the most popular species studied is Candida albicans. Biofilm is developed on various medical devices such as dentures, neurosurgical shunts, speech prostheses, breast implants, prosthetic joints, endotracheal tubes, intracardiac prosthetic devices, urinary catheters, dialysis catheters for peritoneal and hemodialysis, peripheral and venous catheters ${ }^{43}$. It exists in various types, such as yeast, hyphae, and multicellular biofilm ${ }^{44}$. Candida albicans adherence and colonization to denture acrylic substrates as well as oral mucosa is the first step of pathogenesis ${ }^{45-48}$. Candida albicans' initial attachment to the surface is limited by the $\mathrm{pH}$, osmolarity, flow of the nearby medium, such as urine, antimicrobial agents, bacteria, saliva, Mucus, temperature, blood, as well as the host immune factors ${ }^{49-54}$. Candida albicans biofilm formation having different phases of development. It contains substrate adhesion, colonization, extracellular material production,

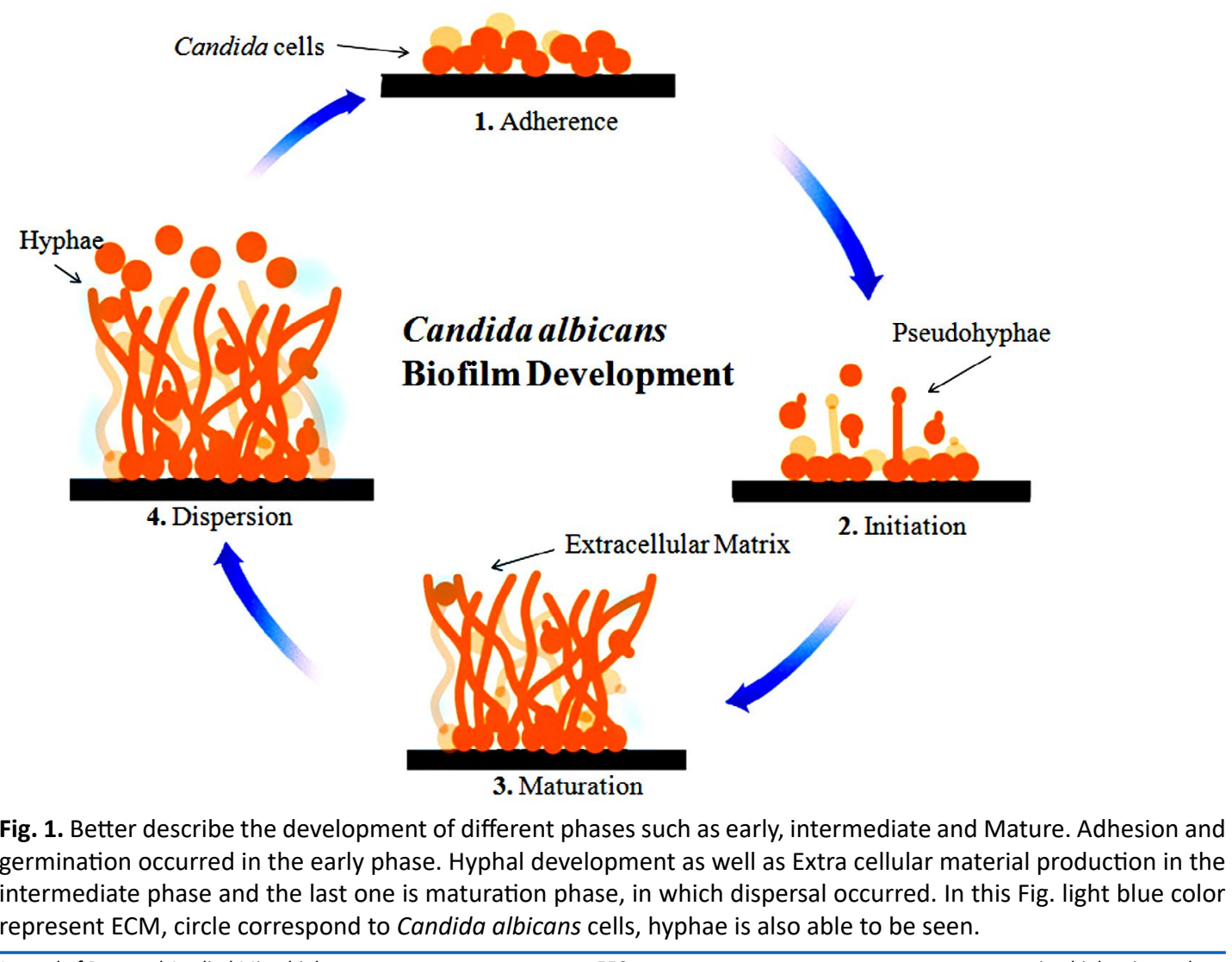


and maturation ${ }^{53-62}$. Biofilm development has been shown in Fig. 1.

The yeast cell's ability to shape biofilms on the implanted medical devices or on the surface in the host enhances its virulence. Candida albicans adhere to the surface with the support of Eap1p (cell wall protein) and Als3p (agglutinin like sequence protein) ${ }^{63,64}$. Als3p and Eap1p are initiations to the formation of microcolonies and further Efg1 regulatory protein is essential for the production of biofilm and its development of pseudo-and true-hyphae to form a complex association of hyphal structures with budding yeast-like cells spread throughout ${ }^{52,65}$. Further, the growth and the maturation of Biofilms, Candida albicans biofilm cells encompass a betaglucan rich extracellular matrix that protects from environmental stresses, antimicrobial agents, and host defenses ${ }^{66}$. The existence of the hypoxic environment is correlated with the maturation of biofilm and this condition induces
Tye7p-dependent up-regulation of glycolytic genes required to respond to hypoxia and prevent uncontrolled hyphal formation ${ }^{67}$. In the final step, planktonic yeast cells dispersed from the mature biofilm and established a new colony on a new surface to grow a new biofilm from Candida ${ }^{68}$. Candida albicans Biofilm formation has been presented in Fig. 2.

The diverse transcription factors such as Efg1p, Ace2p, Zap1p, and Bcr1p are the regulator which controlled the formation of Biofilm ${ }^{63,69-71}$. The various genes have been presented in Fig. 2, for controlling and maintaining the development of biofilm. The most important thing is to understand the mechanism of those genes so inhibition such kind of infections in the populations. The key sites of the infections are biomaterials ${ }^{43}$, wounds ${ }^{72}$, Urinary tract ${ }^{73,74}$, Gastrointestinal tract ${ }^{75}$, lower respiratory $\operatorname{tract}^{76}$, upper respiratory $\operatorname{tract}^{77,78}$, oral cavity $^{79}$, etc.

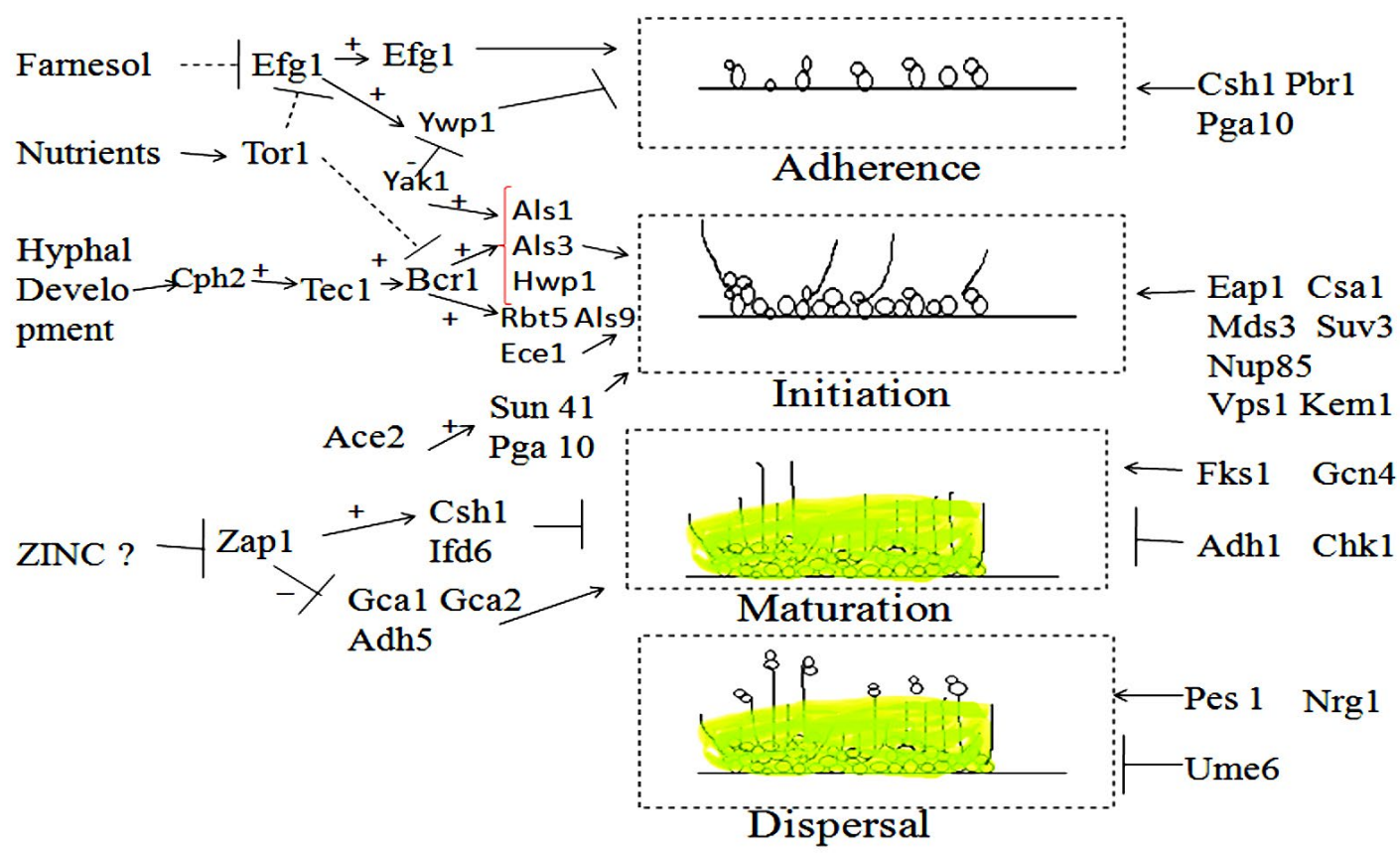

Fig. 2. Different genes are presented here which showed function in Biofilm formation. It has four steps (I) Adherence, (II) initiation, (III) maturation, and (IV) dispersal. In the right-hand side part of the diagram, the genes are connected and involve in pathway but in the left hand side part, the genes may not attach to an established pathway but function in a particular step. Arrows signify positive connection, the Dashed line signify repression by an indirect mechanism. "+" sign indicates that an upstream gene stimulates the expression of the downstream target and "-" sign is opposite of it. "T-shaped" indicated a negative relationship (repression by an indirect process). 


\section{Candida albicans: NMT [N-Myristoyl-transferase] as a drug target}

Post-translational modification is a very important step for proteins to function in a specific way through further modification. Post-translational modification occurs at the protein's C- or N-terminal or on the amino acid side chain ${ }^{80}$. The modification occurs during the post-translational modification are different according to the different transformation such as $\mathrm{C}$ terminal amidation, $\mathrm{N}$-terminal acetylation, phosphorylation of threonine, tyrosine or serine residues mainly in kinases, methylation of arginine and lysine residues mostly in histones, acylation of lysine residues and oxidation mainly in proline residues ${ }^{81}$. A less common type of posttranslational modification is lipidation. Lipidation is the covalent attachment of the lipid moiety to the protein. Lipidation increases stability, membrane interaction, protein hydrophobicity, changes in conformation, trafficking, etc. Different types of lipidation are known, differing according to the group being attached and the position of attachment ${ }^{82}$. Lipidation attachment has been presented in (Table 1).

Regarding the attachment of longer chain fatty acid acylation, myristoylation (attachment of linear chain c-14), and palmitoylation (c-16) ${ }^{86,87}$. Researchers did extensive research and identified
Candida albicans as an antiviral and antifungal therapy target. $\mathrm{N}$-myristoyl transferase is indeed a monomeric cytosolic enzyme that is vital for the function and growth of fungi ${ }^{88,89}$. NMT is present in eukaryotes such as animals, protozoa, and fungi excluding bacteria. Protein N-myristoyl transferase is associate with the Gcn5-related $\mathrm{N}$-acetyltransferases superfamily ${ }^{90}$. Candida albicans NMT contains 451 residues of amino acids and $45 \%$ of the human enzyme sequence identity. NMT is a compact globular, wedge-formed structure in which a big saddle-shaped betasheet present and it occupies the center of the protein structure, also, it is surrounded by several helices means consisting of an $\mathrm{N}$-terminal strand, preceded by two helices, three anti-parallel beta strands, preceded by a signature (central helix) and last beta-strand ${ }^{91}$. The NMT protein structure has been illustrated in Fig. 3. C-terminal half is crucial for the peptide binding site and $\mathrm{N}$-terminal half is important to form mainly Myristoyl-CoA binding site ${ }^{90}$. N-Myristoyl-transferase catalysis reaction is catalyzed by $\mathrm{N}$-myristoyl-transferase, the co-translational addition of myristic acid (14-C saturated fatty acid) to the $\mathrm{N}$-terminal Glycine (GLY) residue of the substrate protein via amide bonding. The $\mathrm{N}$-myristoyl transferase catalysis reaction is performed by the ordered $\mathrm{Bi}-\mathrm{Bi}$ reaction mechanism, the enzyme forming

Table 1. Representation of the structures of lipidation attachments

Sttachment to the Post translation


a high binary selectivity complex (Myristol-CoANMT). This binary complex is essential to the further interaction of $\mathrm{N}$-Myristoyltransferase with peptide and produces a ternary complex recognized as NMT-Myristoyl-CoA-Peptide, following the catalytic transfer of myristate to the peptide substrate. The first free CoA is released, followed by the $\mathrm{N}$-myristylated protein. In general, Myristoylation is irreversible as well as a significant post-translational modification is defined as $\mathrm{N}$-terminal lipidation of eukaryotic and viral proteins ${ }^{92}$. Myristoylation mechanism has been shown in Fig. 4.

Myristoylation involved in anchoring and directing proteins to membranes and their effects such as signal transduction, cellular regulation, numerous pathologic processes caused by viruses, apoptosis, and translocation ${ }^{93,94}$. The binding of

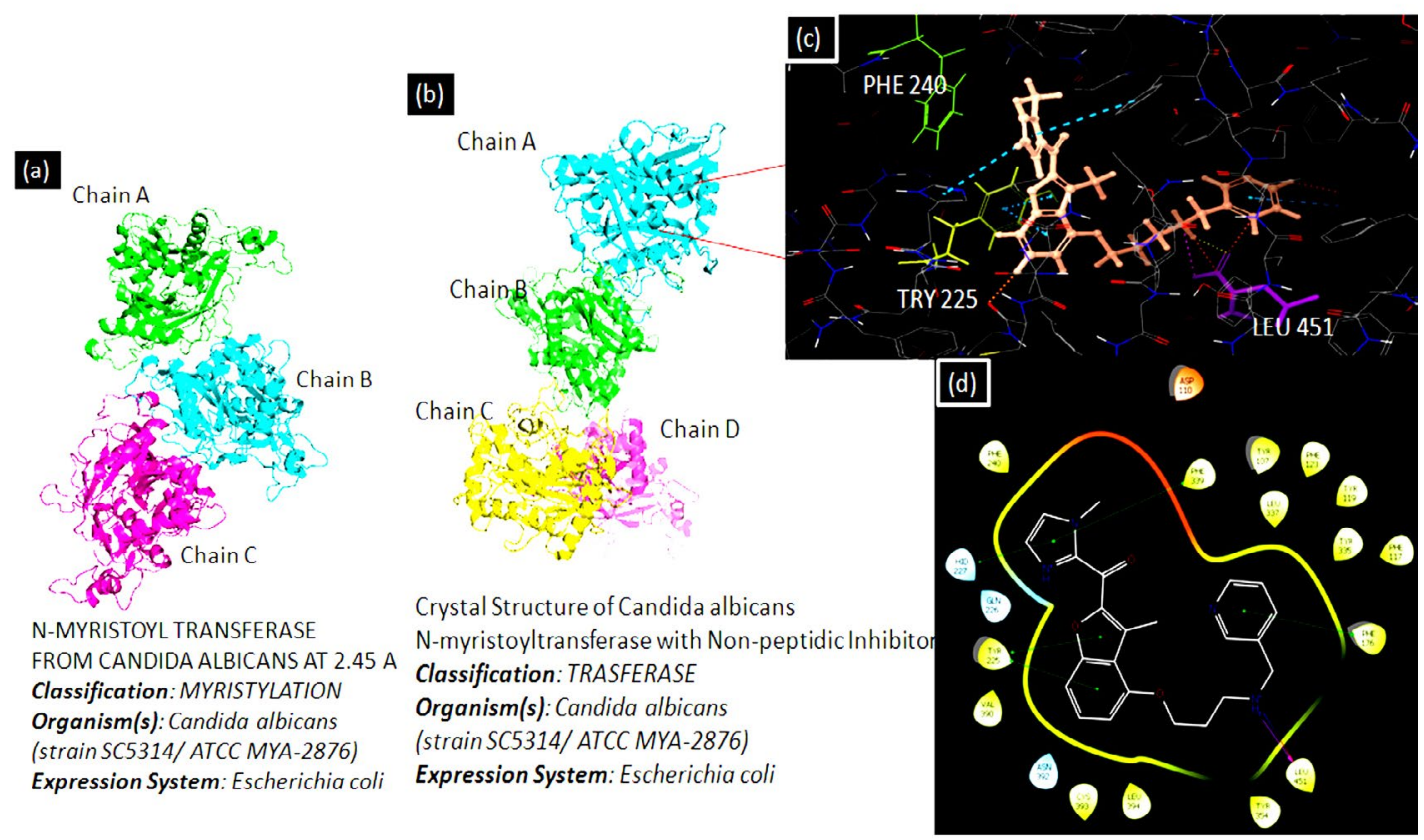

Fig. 3. PDB ID [1NMT] represents NMT from Candida albicans species at $2.45 \mathrm{Ao}$ and PDB ID [1IYL] represents Candida albicans NMT with Non-peptidic Inhibitor. The Ligplot interaction diagram has been generated using the Schrodinger software suit. The ligand is showing its major interaction with a certain amino acid such as PHE 240, TRY 225, and LEU 451.

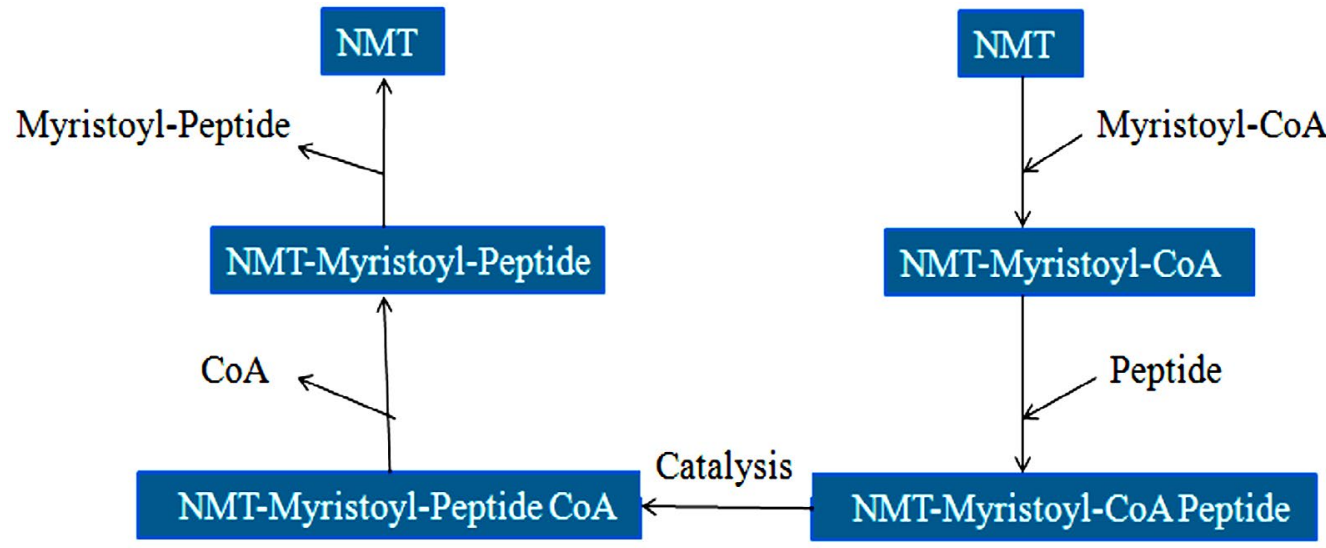

Fig. 4. The catalytic mechanism (Bi-Bi Reaction) of NMT. 
myristoyl residues enables hydrophobicity to affect protein partitioning to the cell membrane and promote the interaction of protein-proteins. It is important for the overall biological expression of viral and cellular protein activity ${ }^{95-97}$. In Fungi, the myristoyl is associated with the cellular membrane and myristoyl-protein interactions. This protein takes part in protein and vesicular trafficking and signals transduction cascade. In Candida albicans with defective NMT unable to infect mice ${ }^{98,99}$. Genetic studies showed that the enzyme is important for pathogenic Candida albicans to grow vegetatively ${ }^{100}$. NMT is a good antifungal agent target because it is responsible for systemic fungal infections and lacking its expression is related to significantly decrease cell growth and increased cell death.

\section{Candida albicans: NMT inhibitors}

Several potent and selective inhibitors have been identified against Candida albicans NMT which showed low inhibitory activity against hNMT. All NMT polypeptides have similar folding but different inhibitor binding sites because of their particular amino acid differences ${ }^{90,101-104}$. As we studied earlier that NMT is responsible for the survival and growth of diverse fungal species, therefore so many different inhibitors have also been identified for reducing its fungal activity such as Benzofurans inhibitors ${ }^{101-103}$, Benzothiazole inhibitors ${ }^{104}$, Myristic acid analogs ${ }^{105,106}$, Peptidomimetic inhibitor ${ }^{88,107}$, p-toluene sulphonamide inhibitors ${ }^{108}$, etc. Devadas et al. reported a peptidomimetic inhibitor against Candida albicans NMT. This inhibitor was structured dependent on octapeptide substrate GLYASKLS-NH2 that was obtained from the $\mathrm{N}$-terminal fragment of ARF2 (ADP ribosylation factor 2) and its analogous ALYASKLS-NH2 ${ }^{107}$. Due to the lower antifungal activity of peptidomimetic inhibitors, Devadas et al. explored new forms of non-peptide inhibitors which represent simply one chiral core and demonstrate fungicidal activity ${ }^{109}$. Parang et al. have tested myristic acid analogs as putative inhibitors of NMT. Quite a lot of (+)-2-halotetradecanoic acids including (+)-2-bromotetradecanoic acid presented strong activity against Candida albicans (MIC $=39 \mu \mathrm{M}$ ). These compounds illustrated antifungal action

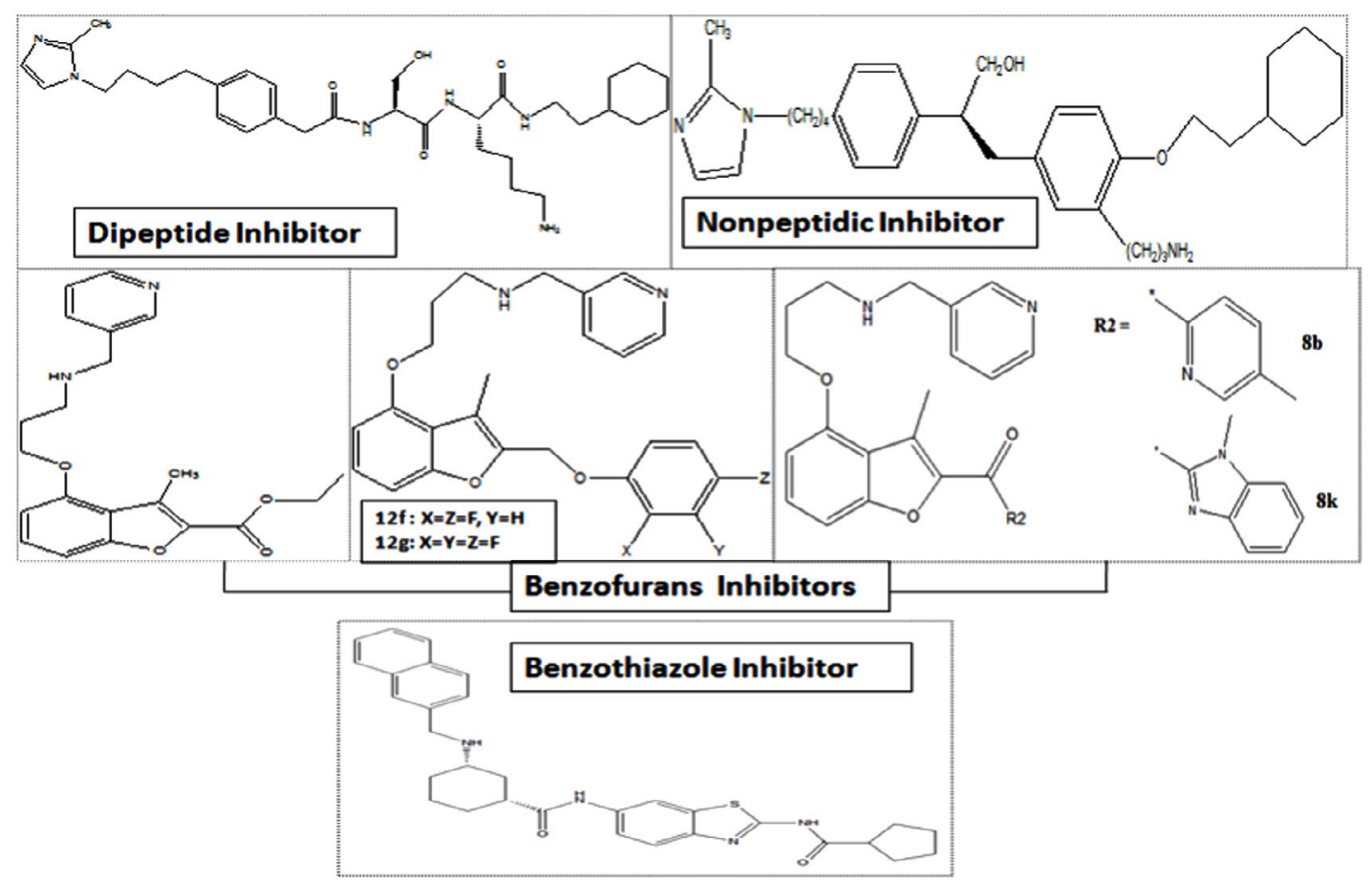

Fig. 5. Candida albicans NMT inhibitors. 
in vitro but not showed in vivo ${ }^{106}$. A new class of inhibitor was also reported named as p-toluene sulfonamides ${ }^{110}$.

In the journey of finding out the novel compounds with high selectivity, Benzofurans and Benzothiazoles are more promising than the previously reported compounds ${ }^{102-104}$. From the viewpoint of the development of antifungal drug candidates, other inhibitors were also developed such as 4-arylthiosemicarbazides derivatives ${ }^{22}$, novel benzofuran-semicarbazide hybrids and 1,3-dialkoxybenzene-semicarbazide hybrids, etc. ${ }^{111}$. Candida albicans NMT inhibitors are presented in Fig. 5.

\section{MATERIALS AND METHODS}

Computational drug discovery approaches really works for finding out the novel agents as new medications. Day by Day pharmaceutical and biotech companies are growing to help the society but the major problems we have to face today is the cost of the drugs are increasing and the expenses which we have to pay for the medicine are increasing. The drug productivity measures are unable to meet the increasing demands. Thus, advanced bioinformatics tools and techniques were discussed to find out the novel antifungal agents using drug repurposing approach.

\section{Virtual Screening and molecular docking}

Protein-ligand docking is a technique commonly used to determine a drug candidate's binding orientation to their specific target. In our survey, we are in consideration of Candida albicans NMT as a drug target for drug designing purpose. Typically molecular docking technique is performed either to searched out that how a specific ligand molecule bind to a target protein or illustrate binding interaction with the targetspecific amino acid residues either H-bonding, Hydrophobic interaction, disulfide bond formation, salt bridge, pi-pi interaction or to find out the potent compound from the available databases that can bind with the target protein ${ }^{112-119}$. The docking can be categorized into two key steps, the initial positioning of the ligand structure at the active site of the target protein using the docking algorithm. followed by uses of the scoring function to assess the potency of the binding interaction. There are a huge number of docking algorithms, tools, techniques are available to highlight the diverse orientation of the interaction between the ligand and the target structure as shown in (Table 2).

In the early days, the docking algorithm did not treat the protein and ligand as flexible objects, only the six translations and also the

Table 2. List of the protein-ligand docking software

\begin{tabular}{|c|c|c|c|c|}
\hline S. No. & $\begin{array}{l}\text { Docking } \\
\text { Programs }\end{array}$ & $\begin{array}{l}\text { Conformational searching } \\
\text { methods }\end{array}$ & $\begin{array}{l}\text { Scoring } \\
\text { Function }\end{array}$ & Investigated by \\
\hline 1. & AutoDock & Genetic algorithm & Empirical & (Morris et al., 1998) $)^{120}$ \\
\hline 2. & Dock & Incremental construction & Force field & (Ewing et al., 2001) \\
\hline 3. & FlexX & Incremental construction & Empirical & (Rarey et al., 1996) ${ }^{122}$ \\
\hline 4. & Glide & $\begin{array}{l}\text { Incremental construction / } \\
\text { Monte Carlo optimization }\end{array}$ & Empirical & $(\text { Friesner et al., 2004) })^{112}$ \\
\hline 5. & Gold & Genetic Algorithm & Force field & (Jones et al., 1997) \\
\hline 6. & Surflex & $\begin{array}{l}\text { Incremental construction, } \\
\text { surface-based molecular } \\
\text { similarity }\end{array}$ & Empirical & (Jain, 2003) $)^{124}$ \\
\hline 7. & ICM & Monte Carlo simulation & $\begin{array}{l}\text { Force field/ } \\
\text { Empirical }\end{array}$ & (Abagyan et al., 1994) \\
\hline 8. & LigandFit & Monte Carlo Simulation & Empirical & (Venkatachalam et al., 2003) \\
\hline 9. & eHiTs & Exhaustive systematic & $\begin{array}{l}\text { Knowledge- } \\
\text { based/ } \\
\text { Empirical }\end{array}$ & (Zsoldos et al., 2007) $)^{127}$ \\
\hline
\end{tabular}


rotational degree of freedom was incorporated. Currently, we are having more consistent docking methods which give the options for flexible docking that the target protein is treated as fixed during the docking process, but the ligand is capable to move around the target.

In this situation, the active site of the protein shall not be considered to undergo any significant changes in conformity with the binding of the ligand. The flexible docking is broadly used with parallel computing resources to relatively, accurately, and quickly search databases for potential ligands to a target protein. The more precise algorithms which consider both ligand and receptor flexibility are very time-consuming, therefore have not been developed extensively. The algorithm which treats flexibility of the ligand is partitioned into three categories, for example, stochastic methods, systematic methods, and simulation methods. The docked poses are ranked and assessed using docking scoring functions which estimate a ligand's binding free energy to a receptor, which is very important to differentiate the right poses from incorrect ones. The scoring function incorporates diverse sorts of terms that express electrostatic interactions, solvation effects, non bonded interactions, and van der Waals interactions ${ }^{128}$. The structure-based virtual screening framework was presented in Fig. 6.

\section{Pharmacophore modeling}

The initial idea of a pharmacophore was developed by Paul Ehrlich during the late 1800s. The theory in the past was that in a molecule there were some chemical groups or functions that were responsible for a biological effect and that certain effect molecules even had similar functions. Fig. 7, revealed the pharmacophore, with its applications. Later in 1960, Schueler coined the term pharmacophore in his book "Chemobiodynamics and Drug Design". It elucidated that a molecular structure that expresses the essential characteristics liable for the biological activity of the drug. The Pharmacophore has been illustrated by IUPAC since $1997^{129}$.

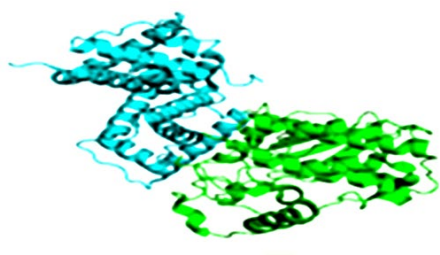

Protein Preparation

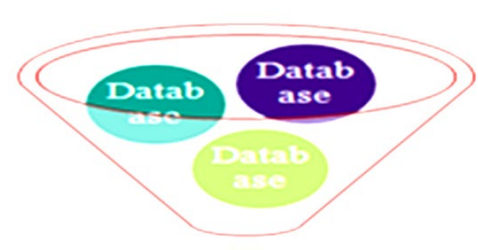

Ligand Preparation

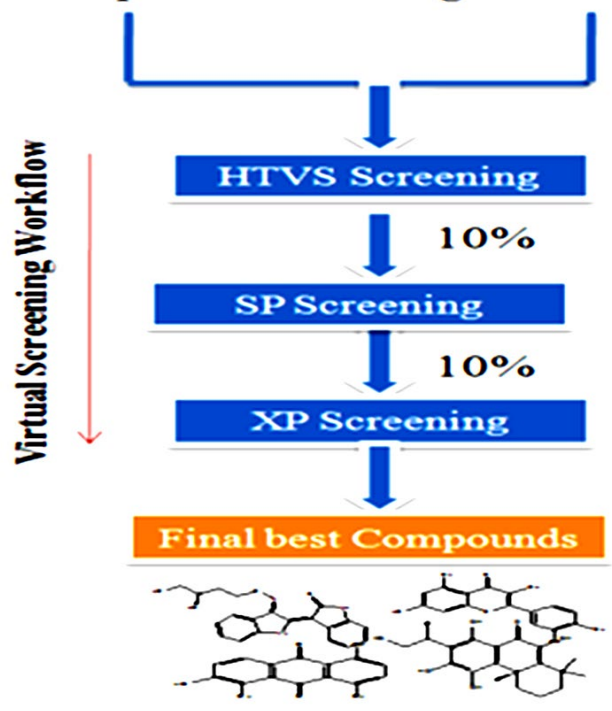

Fig. 6. Structure-based virtual screening Framework. 


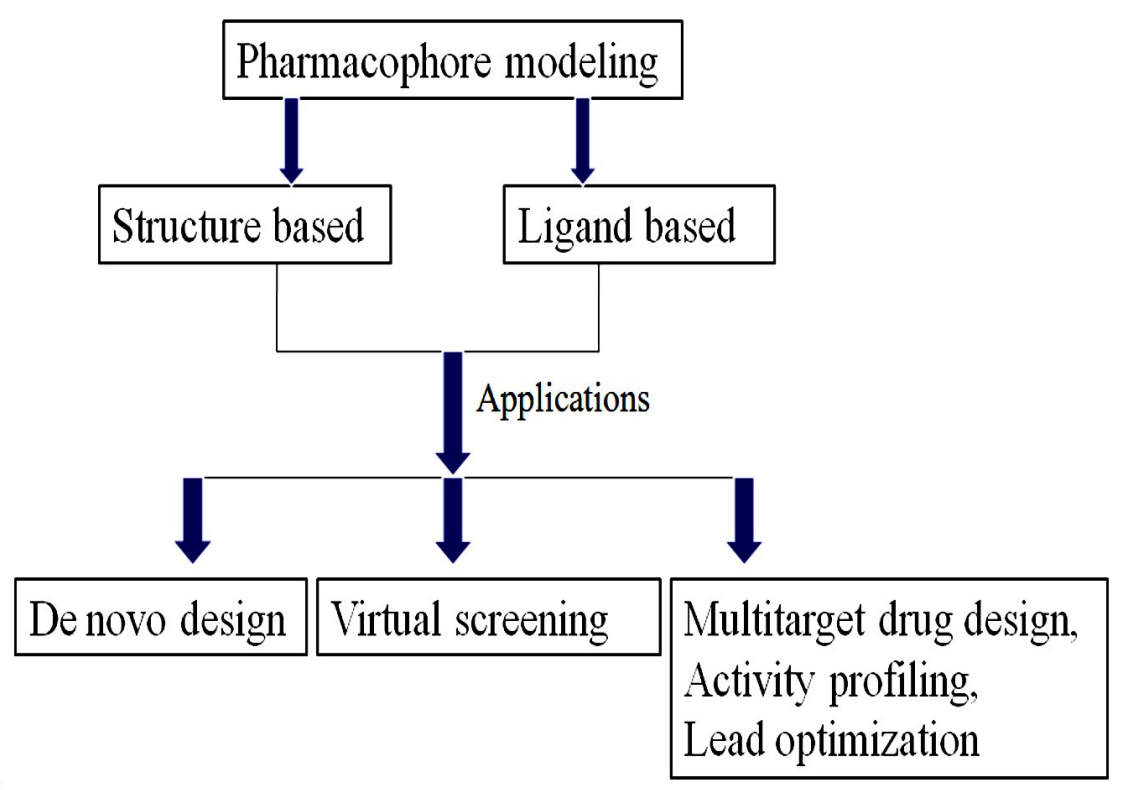

Fig. 7. Pharmacophore modeling and its application.

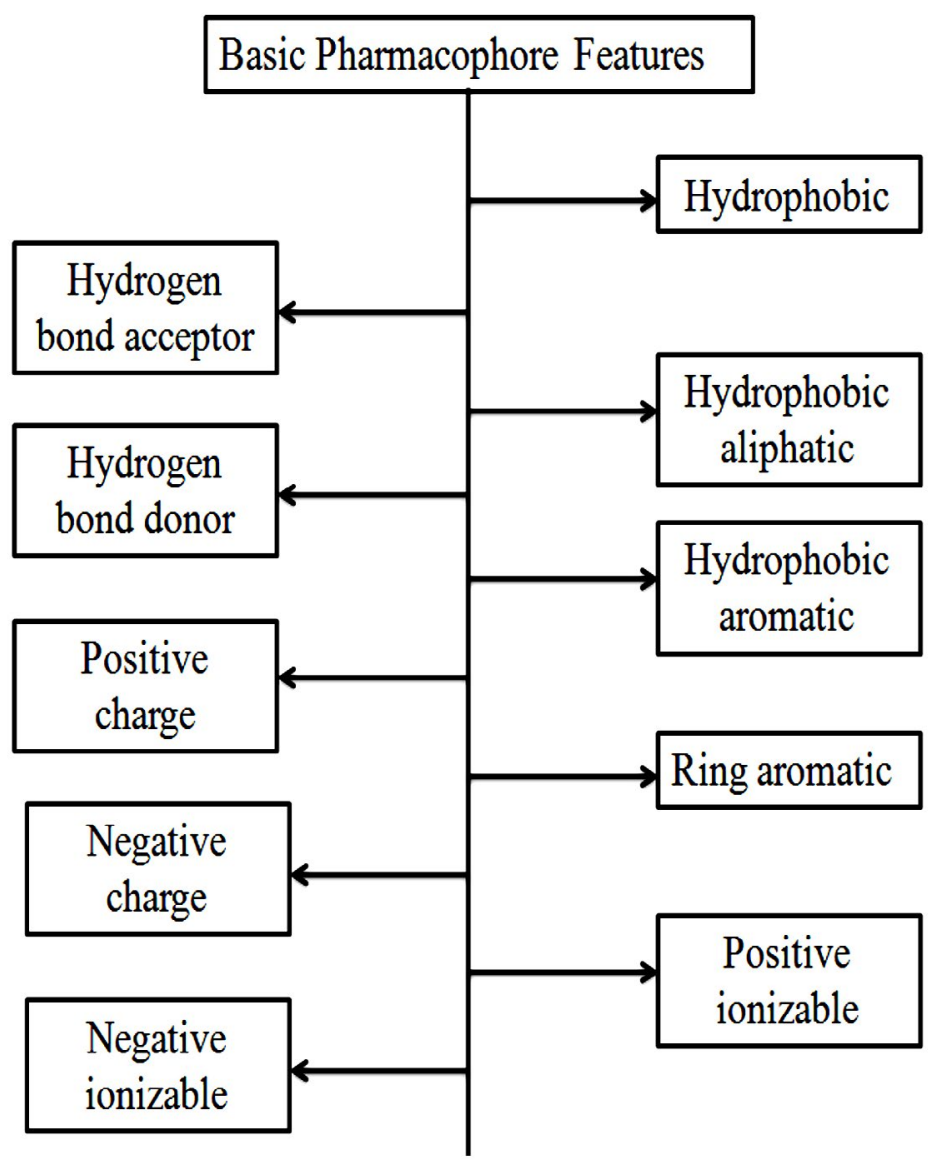

Fig. 8. Basic Pharmacophore features of a molecule. 
It projected that a pharmacophore is the collection of features known steric and electronic that are original to ensuring the mainly desirable supramolecular contacts linked with the desired protein target and blocking its biological activity ${ }^{130}$. The pharmacophore reveals an abstract idea. it relies on the features shared by a group of active molecules or it is the pattern of the features of a molecule that is responsible for a biological effect. Forms of molecular features patterns are hydrogen-bond acceptors, hydrogen-bond donors, hydrophobic, anionic, cationic, aromatic plus any such type of possible combinations presented in Fig. 8.

\section{Pharmacophore modeling (Structure-based)}

The structure-based approach to pharmacophore modeling describes the relevant presentation of important interactions in a proteinbinding pocket. This pharmacophore modeling is appropriate in aspects of a free structure or a complex target-ligand structure. The free structure is classified as apo, and the holo known as the target-ligand complex. The structural pharmacophore modeling was performed using free ligand without protein, using only proteinactive site details and when the pharmacophore modeling uses protein-ligand structure complexes utilize the possible interactions involving protein and ligand, shown in Fig. 9. Structure-based pharmacophore modeling is a very effective tool for virtual screening such as multi-target drug design, scaffold hopping, parallel screening, QSAR, and multi-target drug development ${ }^{131,132}$.

\section{Pharmacophore modeling (Ligand-Based)}

Pharmacophore modeling based on ligand structure is a powerful computational tool of great importance for helping to discover a new drug compound. It is done by extracting the important and crucial chemical features, among the set of ligands. The ligands have been divided into training and test for alignment and generating a pharmacophore model, presented in Fig. 10. This model can be utilized further for the virtual screening process for finding a similar feature molecule that behaves like a drug ${ }^{133,134}$.

Software available for performing pharmacophore modeling

There are diverse software and tools are available to perform structure and ligandbased pharmacophore modeling, presented in (Table 3-4).

\section{Scaffold Hopping}

Schneider et al. (1999) presented Scaffold hopping, in 1999. It is a method for the discovery

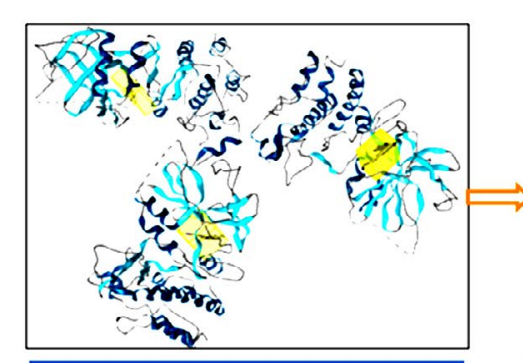

Retrieval of protein-ligand complex

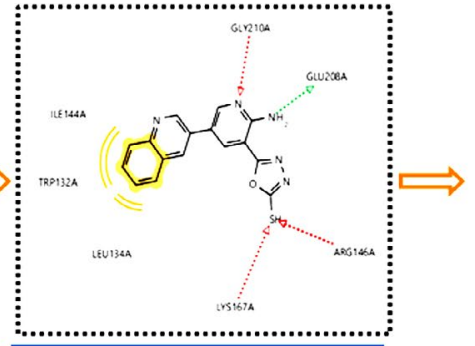

Feature extraction from ligand-protein active site interaction

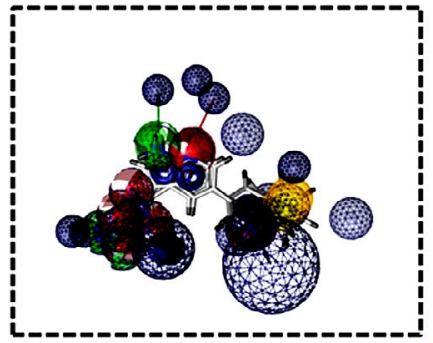

Generation of Common feature pharmacophore model

Fig. 9. Structure-based Pharmacophore modeling and its applications. 
Ligand 1

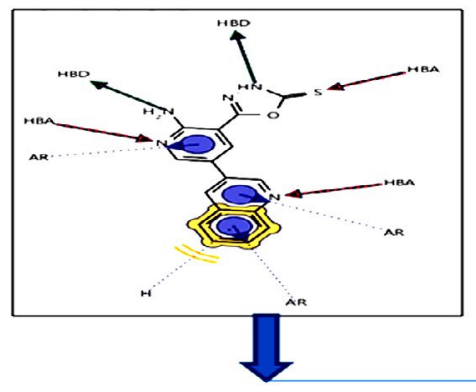

Ligand 2

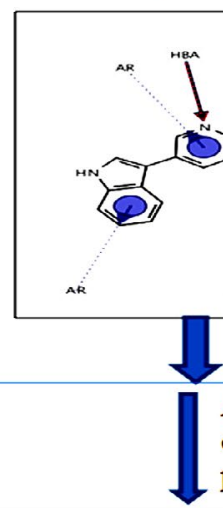

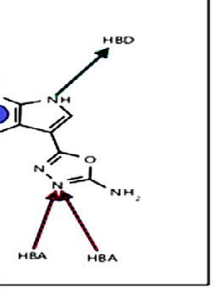

Alignment \& generation

of common feature

pharmacophore

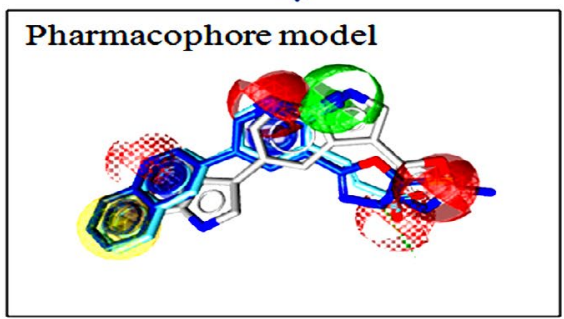

Fig. 10. Representation of ligand-based Pharmacophore modeling.

Table 3. Structure-based pharmacophore modeling software

\begin{tabular}{lcccc}
\hline S. No. & Software & Molecular Alignment & Commercialization & References \\
\hline 1. & LigandScout & Complex-based & Marketed by Inte: Ligand & 135 \\
2. & GBPM & Complex-based & Not commercialized & 136 \\
3. & Pocket v.2 & Complex-based & Not commercialized & 137 \\
\hline
\end{tabular}

Table 4. Ligand-based pharmacophore modeling software

\begin{tabular}{|c|c|c|c|c|}
\hline S. No. & Software & $\begin{array}{l}\text { Molecular Alignment } \\
\text { (methods) }\end{array}$ & Commercialization & Reference \\
\hline 1. & DISCO & $\begin{array}{l}\text { Bron-Kerbosh Clique } \\
\text { detection algorithm }\end{array}$ & Tripos Inc., Sybyl interface & 138 \\
\hline 2. & APOLLO & Feature-based & Not commercialized & 139 \\
\hline 3. & GALAHAD & Atom-based & Tripos Inc., Sybyl interface & 140 \\
\hline 4. & НipHOP & Feature-based & Discovery Studio (Biovia) & 138 \\
\hline 5. & MOE & Property-based & Chemical Computing Group & 141 \\
\hline 6. & MPHIL & Atom-based & Not commercialized & 142 \\
\hline 7. & HypoGen & Feature-based & Discovery Studio (Biovia) & 143 \\
\hline 8. & HypoRefine & Feature-based & Discovery Studio (Biovia) & 144 \\
\hline 9. & Apex-3D & Feature-based & Catalyst (Biovia) & 145 \\
\hline 10. & CLEW & Feature-based & Not commercialized & 146 \\
\hline 11. & GAMMA & Atom-based & Not commercialized & 147 \\
\hline 12. & GASP & Atom-based & Tripos Inc., Sybyl interface. & 138 \\
\hline 13. & PHASE & Feature-based & Schrodinger Inc. & $148-149$ \\
\hline 14. & PharmaGist & Feature-based & http://bioinfo3d.cs.tau.ac.il/PharmaGist/ & 150 \\
\hline 15. & LigandScout & $\begin{array}{l}\text { Matching pattern- } \\
\text { based alignment }\end{array}$ & Marketed by Inte: Ligand & 151 \\
\hline
\end{tabular}


of isofunctional molecular structures by way of considerably different molecular backbones ${ }^{152}$. Traditionally, a large fraction of the medicines produced is extracted from natural hormones, other medications, and natural products by scaffolding modification ${ }^{153}$. Recently published papers and reviewing these relevant examples provide useful guidance for a medicinal chemist for developing a new bioactive molecule. Scaffold hopping, also known as lead hopping ${ }^{154,155}$. It is one of those approaches for finding out the new lead candidates ${ }^{156}$. Scaffold hopping intends to discover a structurally novel substance structure starting from previously identified active compounds by altering the center core structure of the molecule ${ }^{157}$. Scaffold hopping is commonly used in lead optimization. Since using HTS, so many compounds are unsuccessful compounds with poor PK properties and poor physiochemical properties. To overcome this, side-chain modification is sufficient sometimes, the core structure of the parent molecule or the scaffold may often be changed ${ }^{152,158-160}$.

\section{Why Scaffold hopping is so important}

- Central scaffolds are also specifically involved in target protein interactions. An enhanced binding affinity can result from a change in the scaffold.

- Replacing a lipophilic scaffold by an extra polar one could enhance the solubility of the compounds (lipophilic compound soluble in fats, oils, lipids etc. for increasing solubility, lipophilic scaffold can be change by an extra polar side chain or fragment).

- $\quad$ Replacing a very flexible scaffold known as peptide backbone by an inflexible central scaffold would also considerably advance the binding affinity and on the total DMPK characteristics.

- Changes in the core of the structure may lead to a patentable novel compound.

- Replacing a metabolically labile scaffold via a reduced amount of toxic, and an additional stable one will improve pharmacokinetic properties.

\section{Insilico approaches for scaffold hopping}

There are different approaches are available for scaffold hopping but the main idea behind is (1) matching of shape, (2) searching for pharmacophores, (3) replacement of fragments, (4) looking for similarities, and (5) machine learning, etc.

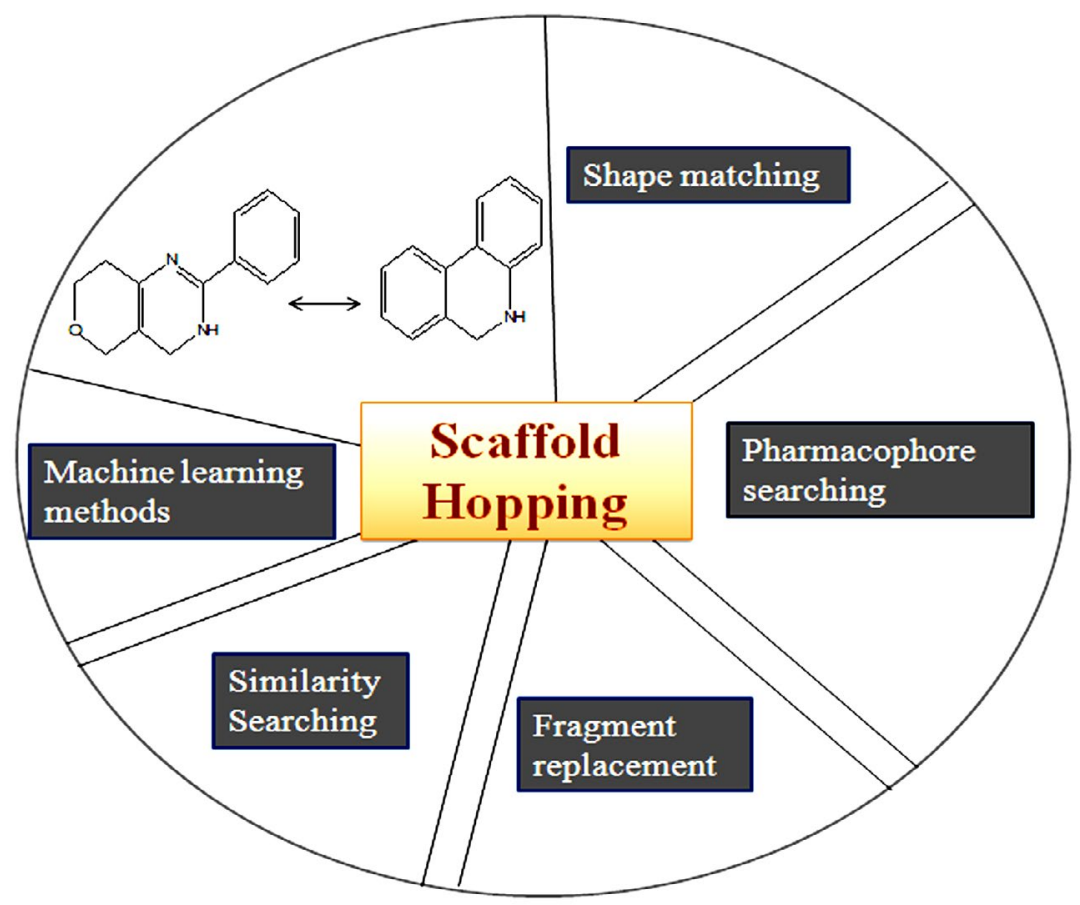

Fig. 11. Scaffold hopping: Computational Approaches. 
The Shape matching approach describes if the compounds are structurally related means display similar biological activities and if the compounds are more distantly related, the less probable to show the same biological effects. In shape matching, it is possible to find out the compounds which mimic accurately this structure, but it is not possible to get the same features that are significant for binding to the target structure ${ }^{161,162}$. If the ligands are structurally different however, can adopt similar shape and share common features, It is possible to derive 3D pharmacophores, which is used for shape matching scaffold hopping.

But the drawback is for searching out the 3D pharmacophore using different chemical structure databases is not sufficient to find out the novel scaffold because it searches from the known compound databases ${ }^{163-166}$. Another approach to scaffold hopping is fragment replacement, in which no need for the replacement of the entire compounds but searching for a replacement of fragment of an active compound ${ }^{167-169}$. Similarity searching is also used for scaffold hopping. The chemical structures are assembled in these algorithms using fragment joining as well as the novel scaffolds are resolved by their match to the query ${ }^{170-172}$. Also, machine learning methods are used for scaffolds hopping, methods together with self-organizing maps that allow compound distributions to be visualized ${ }^{173,174}$. The computational methods of scaffold hopping are shown in Fig. 11. The software tools is listed out in (Table 5).

\section{Molecular Simulations And Advancement}

Since the first protein (folded globular protein) MD simulation is discussed in $1977^{186}$. In December 1999, IBM declared a five-year intend to build up a massively parallel computer for studying biomolecular phenomena, in which they

Table 5. List of Software and tools for scaffold hopping

\begin{tabular}{|c|c|c|c|}
\hline S.No. & Software \& tools & Applications & Ref. \\
\hline 1. & $\begin{array}{l}\text { 1-Click Scaffold } \\
\text { Hop }\end{array}$ & It is ready to use drug discovery platform for scaffold hopping & 175 \\
\hline 2. & Spark ${ }^{\mathrm{TM}}$ & $\begin{array}{l}\text { Spark works in Shape space and electrostatic so it can go with the } \\
\text { nature of reference molecules }\end{array}$ & 176 \\
\hline 3. & Core Hopping & $\begin{array}{l}\text { The core-hopping technique is to test several possible scaffolds } \\
\text { as protocores) against a template and look for alignments of possible } \\
\text { (also known attachment points on the scaffold with the attachment } \\
\text { points on the template. }\end{array}$ & 177 \\
\hline 4. & LigCSRre & $\begin{array}{l}\text { LigCSRre is a modern effective and standardized method for 3D } \\
\text { matching screening of tiny compounds, the modular plan of which } \\
\text { opens the door to lots of improvements. }\end{array}$ & 178 \\
\hline 5. & e-LEA3D & $\begin{array}{l}\text { The approach is perfectly appropriate for scaffold-hopping, this section } \\
\text { moreover permits a search for potential substitutes to a selected scaffold. }\end{array}$ & 179 \\
\hline 6. & ChemMapper & $\begin{array}{l}\text { ChemMapper using the user given the chemical structure of the molecules } \\
\text { as the query, the highest alike structure in respect of 3D similarity is sent } \\
\text { back using related pharmacology annotations. }\end{array}$ & 180 \\
\hline 7. & SHOP & $\begin{array}{l}\text { It is a grid-based technique for Scaffold bouncing. In a database, scaffolds } \\
\text { were predictable utilizing } 3 \text { types of 3D-descriptors. }\end{array}$ & 181 \\
\hline 8. & LeadGrow+ & Creating a molecular library for efficient scaffold hopping. & 182 \\
\hline 9. & Recore & $\begin{array}{l}\text { Recore is a rapid and flexible scaffold hopping method based on } \\
\text { conformations of small molecule crystal structures. }\end{array}$ & 183 \\
\hline 10. & HTSFPS & $\begin{array}{l}\text { (HTSFPs), It is a method that matches patterns of actions in investigational } \\
\text { screens. }\end{array}$ & 184 \\
\hline 11. & MORPH & $\begin{array}{l}\text { MORPH is a software tool for scaffold hopping which can scientifically } \\
\text { alter aromatic rings in molecular 3-dimensional models exclusive change } \\
\text { of the non-hydrogen atom co-ordinates in the rings. }\end{array}$ & 185 \\
\hline
\end{tabular}




\section{Trajectory}

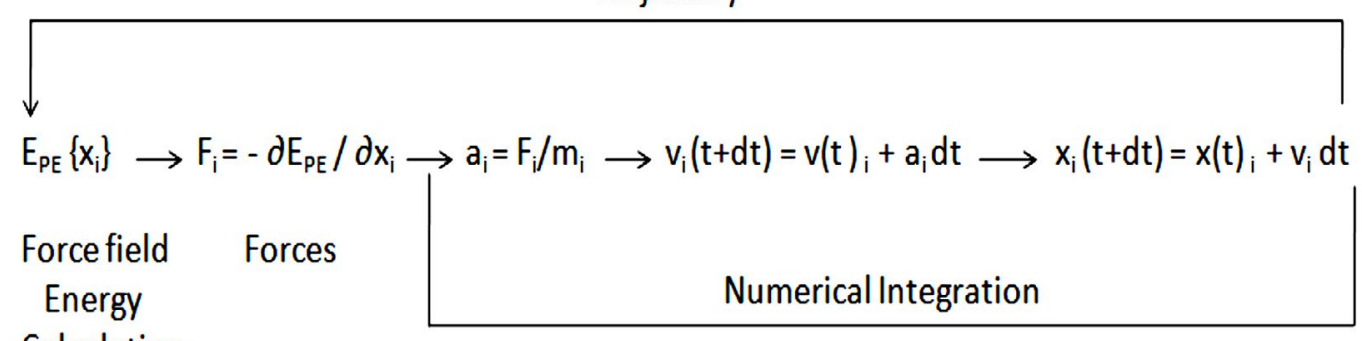

Calculation

$$
\begin{aligned}
& E_{P E}=\text { potential energy } \\
& t=\text { simulation time } \\
& F=\text { forces component } \\
& i=\text { For every spatial coordinate } \\
& \text { of the } N \text { simulated atoms } \\
& x=\text { atom coordinate }
\end{aligned}
$$

$$
\begin{aligned}
& \mathrm{dt}=\text { iteration } \text { time } \\
& \mathrm{a}=\text { acceleration } \\
& \mathrm{v}=\text { velocity } \\
& \mathrm{m}=\text { atom mass }
\end{aligned}
$$

Fig. 12. A Basic algorithm for Molecular Dynamics.

have discussed for increasing longer simulation time as well as developing computing software and hardware for bimolecular MD simulation ${ }^{187}$. Certain software packages were also developed for simultaneously scales well-organized MD simulation very well on machines ${ }^{188}$. A massively parallel machine such as Anton was introduced which was able to reach millisecond time-scale simulation for biomolecular systems ${ }^{189}$. In recent times graphical processing unit which is known as GPU achieved remarkable progress with high-performance computing capability for MD simulations ${ }^{190,191}$. currently, MD simulation is very important for studying protein, DNA, and RNA systems. In the MD simulation so many terms are used in which force field is very significant where a protein force field included bonded (bond angle, dihedral angles, bond length) and also non-bonded interactions (electrostatic, van der Waals). The development of improved sampling methods and escalating computational performance came with more inaccuracies in the protein force field ${ }^{192}$. In these aspects, the classical protein field has been improved with Gromacs ${ }^{188}$, AMBER ${ }^{193}$, CHARMM $^{194}$, and NAMD ${ }^{195}$. A basic algorithm for MD simulation has been represented Fig. 12 and a list of software has been shown in (Table 6). apart from this MD simulation software, there are other software also available such as Desmond ${ }^{196}$, TINKER, DL_POLY ${ }^{197}$, ESPResSo ${ }^{198}$, etc. so that it is understood that MD is already an important tool in serving to understand biology.

\section{RESULTS AND DISCUSSION}

The anticipated outcome could be development and searching out the novel, specific inhibitors for Candida albicans MyristoylCoA: Protein N-Myristoyltransferase as anti-fungal agents using advanced computational approaches. A humble beginning made towards this end needs patronage for further development. All the more interesting on this aspect is, still as on date, no successful attempt has been made towards development of a best, specific inhibitor for Candida albicans MyristoylCoA: Protein $\mathrm{N}$-Myristoyltransferase which again augments support. 
Table 6. List of major Software and tools for MD Simulation

\begin{tabular}{|c|c|c|c|c|}
\hline About & GROMACS & AMBER & CHARMM & NAMD \\
\hline $\begin{array}{l}\text { Developer } \\
\text { (s) }\end{array}$ & $\begin{array}{l}\text { Martin Karplus, } \\
\text { Accelrys }\end{array}$ & $\begin{array}{l}\text { Peter Kollman's, } \\
\text { research group (at } \\
\text { first Developed) at } \\
\text { the University of } \\
\text { California. }\end{array}$ & $\begin{array}{l}\text { Martin Karplus, } \\
\text { Accelrys }\end{array}$ & $\begin{array}{l}\text { The University of Illinois at } \\
\text { Urbana-Champaign }\end{array}$ \\
\hline $\begin{array}{l}\text { Initial } \\
\text { release }\end{array}$ & $1991 ; 29$ years ago & $2002 ; 18$ years ago & $1983 ; 37$ years ago & $1995 ; 25$ years prior \\
\hline Stable & $2018.4 / 12$ & Amber18, & $\mathrm{c} 40 \mathrm{~b} 1, \mathrm{c} 40 \mathrm{~b} 2 /$ & 2.12/December 22, 2016; 3 years \\
\hline release & $\begin{array}{l}\text { November 2018; } 16 \\
\text { months prior }\end{array}$ & $\begin{array}{l}\text { AmberTools19/ } \\
\text { April 26, 2019; } 10 \\
\text { months ago }\end{array}$ & 2015; 5 years ago & ago \\
\hline Written in & $\mathrm{C}++, \mathrm{C}$ & C, C++, Fortran 95 & $\begin{array}{l}\text { FORTRAN 77-95, } \\
\text { CUDA }\end{array}$ & $\mathrm{C}++$ \\
\hline Operating & Linux, Windows & Windows, OS X, & Unix-like: Linux, & Cross-platform: Windows, \\
\hline system & $\begin{array}{l}\text { macOS, some other } \\
\text { Unix variety }\end{array}$ & Linux, Unix, CNK & macOS, AIX, iOS & macOS, Unix \\
\hline Platform & Many & $\begin{array}{l}\text { x86, Nvidia GPUs, } \\
\text { Blue Gene }\end{array}$ & $\begin{array}{l}\text { x86, ARM, Nvidia } \\
\text { GPU; Cray XT4, } \\
\text { XT5 }\end{array}$ & $x 86, x 86-64$ \\
\hline $\begin{array}{l}\text { Available } \\
\text { in }\end{array}$ & English & English & English & English \\
\hline License & $\begin{array}{l}\text { LGPL variants }>= \\
4.6 \text {, }\end{array}$ & Amber: Proprietary & Proprietary & $\begin{array}{l}\text { Proprietary, freeware for } \\
\text { noncommercial use }\end{array}$ \\
\hline & GPL variants $<4.6$ & $\begin{array}{l}\text { AmberTools: } \\
\text { public domain, } \\
\text { GPL, other open- } \\
\text { source }\end{array}$ & & \\
\hline $\begin{array}{l}\text { Website } \\
\text { Sources }\end{array}$ & www.gromacs.org & ambermd.org & www.charmm.org & www.ks.uiuc.edu/Research/namd \\
\hline
\end{tabular}

\section{CONCLUSION AND FUTURE PERSPECTIVE}

$\mathrm{N}$-myristoyl transferase is a monomeric cytosolic protein that is vital for the function and growth of fungi. There are so many inhibitors that have been designed against Candida albicans NMT for reducing fungal infections in humans but at present antifungal drugs are not perfect in the expressions of the antifungal spectrum, efficacy, and protection. Drug repurposing is one of the most significant, more affordable, and increasingly proficient techniques in drug discovery. So right now, we have examined in silico drug repurposing approach which joins Molecular docking, Virtual Screening, Pharmacophore demonstrating, Scaffold hopping, and Molecular dynamics (MD) simulation for the advancement of a novel Candida albicans NMT inhibitors.

\section{ACKNOWLEDGMENTS}

The Authors would like to offer their sincere thanks to ICMR (Indian Council of Medical Research), New Delhi, Government of India, for financial support related help For the present research and Department of Biotechnology (DBT) New Delhi for offering help as Bioinformatics infrastructure facility. The authors also would like to acknowledge the Schrödinger group for giving software support.

\section{CONFLICT OF INTEREST}

The authors declare that there is no conflict of interest.

\section{AUTHORS' CONTRIBUTION}

All authors have made substantial, direct, 
and intellectual contribution to the work and approve it for publication.

\section{FUNDING}

This work was supported by ICMR (Indian Council of Medical Research) Grant number ISRM/11(46)/2019, New Delhi, and Government of India.

\section{DATA AVAILABILITY}

All datasets generated or analyzed during this study are included in this manuscript.

\section{ETHICS STATEMENT}

Not applicable.

\section{REFERENCES}

1. Brown GD, Denning DW, Gow NAR, Levitz SM, Netea MG, White TC. Hidden Killers: Human Fungal Infections. Sci Trans/ Med. 2012;4(165). doi:10.1126/ scitranslmed.3004404

2. Brown GD, Denning DW, Levitz SM. Tackling Human Fungal Infections. Science. 2012;336(6082):647. doi:10.1126/science.1222236

3. Pfaller M, Diekema D. Epidemiology of invasive candidiasis: a persistent public health problem. Clin Microbiol Rev. 2007;20(1):133-163. doi: 10.1128/ CMR.00029-06

4. Negri $M$, Martins $M$, Henriques $M$, Svidzinski TI, Azeredo J, Oliveira R. Examination of potential virulence factors of Candida tropicalis clinical isolates from hospitalized patients. Mycopathologia. 2010;169(3):175-182. doi: 10.1007/s11046-009-92460

5. Roemer T, Krysan DJ. Antifungal drug development: challenges, unmet clinical needs, and new approaches. Cold Spring Harb Perspect Med. 2014;4(5). doi:10.1101/ cshperspect.a019703

6. Perlroth J, Choi B, Spellberg B. Nosocomial fungal infections: epidemiology, diagnosis, and treatment. Med Mycol. 2007;45(4):321-346. doi:10.1080/13693780701218689

7. Rueping MJ, Vehreschild JJ, Cornely OA. Invasive candidiasis and candidemia: from current opinions to future perspectives. Expert Opin Investig Drugs. 2009;18(6):735-748. doi:10.1517/13543780902911440

8. Jacobsen ID, Wilson D, Wachtler B, Brunke S, Naglik JR, Hube B. Candida albicans dimorphism as a therapeutic target. Expert Rev Anti Infect Ther. 2012;10(1):85-93. doi:10.1586/eri.11.152

9. Borg-von Zepelin M, Kunz L, Ruchel R, Reichard U, Weig M, Gross U. Epidemiology and antifungal susceptibilities of Candida spp. to six antifungal agents: results from a surveillance study on fungaemia in Germany from July 2004 to August 2005. J Antimicrob Chemother. 2007;60(2):424-428. doi:10.1093/jac/ $\mathrm{dkm} 145$
10. Panizo MM, Reviakina V, Dolande M, Selgrad S. Candida spp. in vitro susceptibility profile to four antifungal agents. Resistance surveillance study in Venezuelan strains. Med Mycol. 2009;47(2):137-143. doi:10.1080/13693780802144339

11. Richardson M, Lass-Florl C. Changing epidemiology of systemic fungal infections. Clin Microbiol Infect. 2008;14 Suppl 4:5-24. doi:10.1111/j.14690691.2008.01978.x

12. Pappas PG, Kauffman CA, Andes D, et al. Clinical practice guidelines for the management of candidiasis: 2009 update by the Infectious Diseases Society of America. Clin Infect Dis. 2009;48(5):503-535. doi:10.1086/596757

13. Pfaller MA, Diekema DJ, Jones RN, et al. International surveillance of bloodstream infections due to Candida species: frequency of occurrence and in vitro susceptibilities to fluconazole, ravuconazole, and voriconazole of isolates collected from 1997 through 1999 in the SENTRY antimicrobial surveillance program. J Clin Microbiol. 2001;39(9):3254-3259. doi:10.1128/jcm.39.9.3254-3259.2001

14. Wisplinghoff $\mathrm{H}$, Bischoff $\mathrm{T}$, Tallent SM, Seifert $\mathrm{H}$, Wenzel RP, Edmond MB. Nosocomial bloodstream infections in US hospitals: analysis of 24,179 cases from a prospective nationwide surveillance study. Clin Infect Dis.2004;39(3):309-317. doi:10.1086/421946

15. Mean M, Marchetti O, Calandra T. Bench-to-bedside review: Candida infections in the intensive care unit. Crit Care. 2008;12(1):204. doi:10.1186/cc6212

16. Sheehan DJ, Hitchcock CA, Sibley CM. Current and emerging azole antifungal agents. Clin Microbiol Rev. 1999;12(1):40-79. doi: 10.1128/CMR.12.1.40

17. Schiaffella F, Macchiarulo A, Milanese L, et al. Design, synthesis, and microbiological evaluation of new Candida albicans CYP51 inhibitors. J Med Chem. 2005;48(24):7658-7666. doi:10.1021/jm050685j

18. Shapiro RS, Robbins N, Cowen LE. Regulatory circuitry governing fungal development, drug resistance, and disease. Microbiol Mol Biol Rev. 2011;75(2):213-267. doi:10.1128/mmbr.00045-10

19. Wiegand RC, Carr C, Minnerly JC, et al. The Candida albicans myristoyl-CoA:protein $\mathrm{N}$-myristoyltransferase gene. Isolation and expression in Saccharomyces cerevisiae and Escherichia coli. J Biol Chem. 1992;267(12):8591-8598. doi: 10.1016/S00219258(18)42484-2

20. Fazly A, Jain C, Dehner AC, et al. Chemical screening identifies filastatin, a small molecule inhibitor of Candida albicans adhesion, morphogenesis, and pathogenesis. Proc Natl Acad Sci USA. 2013;110(33):13594-13599. doi:10.1073/pnas.1305982110

21. Garcia C, Burgain A, Chaillot J, Pic E, Khemiri I, Sellam A. A phenotypic small-molecule screen identifies halogenated salicylanilides as inhibitors of fungal morphogenesis, biofilm formation and host cell invasion. Sci Rep. 2018;8(1):11559. doi:10.1038/ s41598-018-29973-8

22. Siwek A, Stefanska J, Dzitko K, Ruszczak A. Antifungal effect of 4-arylthiosemicarbazides against Candida species. Search for molecular basis of antifungal activity of thiosemicarbazide derivatives. J Mol Model. 
2012;18(9):4159-4170. doi:10.1007/s00894-0121420-5

23. Paiva JA, Pereira JM. New antifungal antibiotics. Curr Opin Infect Dis. 2013;26(2):168-174. doi:10.1097/ QCO.0b013e32835ebcb7

24. Perfect JR. The antifungal pipeline: a reality check. Nat Rev Drug Discov. 2017;16(9):603-616. doi:10.1038/ nrd.2017.46

25. Wurtele $\mathrm{H}$, Tsao S, Lepine G, et al. Modulation of histone $\mathrm{H} 3$ lysine 56 acetylation as an antifungal therapeutic strategy. Nat Med. 2010;16(7):774-780. doi:10.1038/nm.2175

26. Raj S, Krishnan K, Askew DS, et al. The Toxicity of a Novel Antifungal Compound Is Modulated by Endoplasmic Reticulum-Associated Protein Degradation Components. Antimicrob Agents Chemother. 2015;60(3):1438-1449. doi:10.1128/ aac.02239-15.

27. Alksne LE, Projan SJ. Bacterial virulence as a target for antimicrobial chemotherapy. Curr Opin Biotechnol. 2000;11(6):625-636. doi:10.1016/s09581669(00)00155-5

28. Gauwerky K, Borelli C, Korting HC. Targeting virulence: a new paradigm for antifungals. Drug Discov Today. 2009;14(3-4):214-222. doi:10.1016/j. drudis.2008.11.013

29. Kim K, Zilbermintz L, Martchenko M. Repurposing FDA approved drugs against the human fungal pathogen, Candida albicans. Ann Clin Microbiol Antimicrob. 2015;14:32. doi:10.1186/s12941-015-0090-4

30. Enoch DA, Ludlam HA, Brown NM. Invasive fungal infections: a review of epidemiology and management options. J Med Microbiol. 2006;55(Pt 7):809-818. doi:10.1099/jmm.0.46548-0

31. Blot S, Vandewoude K. Management of invasive candidiasis in critically ill patients. Drugs. 2004;64(19):2159-2175. doi:10.2165/00003495200464190-00002

32. Arendrup MC, Fuursted K, Gahrn-Hansen B, et al. Seminational surveillance of fungemia in Denmark: notably high rates of fungemia and numbers of isolates with reduced azole susceptibility. J Clin Microbiol. 2005;43(9):4434-4440. doi:10.1128/jcm.43.9.44344440.2005

33. Hobson R. The global epidemiology of invasive Candida infections-is the tide turning? J Hosp Infect. 2003;55(3):159-168. doi: 10.1016/j.jhin.2003.08.012

34. Verweij PE, Snelders E, Kema GH, Mellado E, Melchers WJ. Azole resistance in Aspergillus fumigatus: a side-effect of environmental fungicide use? Lancet Infect Dis. 2009;9(12):789-795. doi:10.1016/s14733099(09)70265-8

35. Groll AH, De Lucca AJ, Walsh TJ. Emerging targets for the development of novel antifungal therapeutics. Trends Microbiol. 1998;6(3):117-124. doi:10.1016/ s0966-842x(97)01206-7

36. Costerton JW, Lewandowski Z, Caldwell DE, Korber DR, Lappin-Scott HM. Microbial biofilms. Annu Rev Microbiol. 1995;49:711-745. doi:10.1146/annurev. mi.49.100195.003431

37. Donlan RM. Biofilms: microbial life on surfaces. Emerg Infect Dis. 2002;8(9):881-890. doi:10.3201/

\section{eid0809.020063}

38. Ramage G, Mowat E, Jones B, Williams C, LopezRibot J. Our current understanding of fungal biofilms. Crit Rev Microbiol. 2009;35(4):340-355. doi:10.3109/10408410903241436

39. Donlan RM, Costerton JW. Biofilms: survival mechanisms of clinically relevant microorganisms. Clin Microbiol Rev. 2002;15(2):167-193. doi:10.1128/ cmr.15.2.167-193.2002

40. Sayed SI, Datta S, Deore N, Kazi RA, Jagade MV. Prevention of voice prosthesis biofilms: current scenario and future trends in prolonging prosthesis lifetime. J Indian Med Assoc. 2012;110(3):175-180.

41. Fanning S, Mitchell AP. Fungal biofilms. PLoS Pathog. 2012;8(4):e1002585. doi:10.1371/journal. ppat.1002585

42. Kabir MA, Hussain MA, Ahmad Z. Candida albicans: a model organism for studying fungal pathogens. ISRN Microbiol. 2012;2012:538694. doi: 10.5402/2012/538694

43. Ramage G, Martinez JP, Lopez-Ribot JL. Candida biofilms on implanted biomaterials: a clinically significant problem. FEMS Yeast Res. 2006;6(7):979986. doi: 10.1111/j.1567-1364.2006.00117.x

44. Noble SM, Gianetti BA, Witchley JN. Candida albicans cell-type switching and functional plasticity in the mammalian host. Nat Rev Microbiol. 2017;15(2):96108. doi:10.1038/nrmicro.2016.157

45. Ellepola AN, Samaranayake LP. Adhesion of oral Candida albicans isolates to denture acrylic following limited exposure to antifungal agents. Arch Oral Biol. 1998;43(12):999-1007. doi:10.1016/s00039969(98)00075-2

46. Holmes AR, Bandara BM, Cannon RD. Saliva promotes Candida albicans adherence to human epithelial cells. J Dent Res. 2002;81(1):28-32. doi:10.1177/002203450208100107

47. Radford DR, Challacombe SJ, Walter JD. Denture plaque and adherence of Candida albicans to denture- base materials in vivo and in vitro. Crit Rev Oral Biol Med. 1999;10(1):99-116. doi:10.1177/1045441199010001 0501

48. Williams DW, Kuriyama T, Silva S, Malic S, Lewis MA. Candida biofilms and oral candidosis: treatment and prevention. Periodontol 2000. 2011;55(1):250-265. doi:10.1111/j.1600-0757.2009.00338.x

49. Hawser S, Baillie G, Douglas LJ. Production of extracellular matrix by Candida albicans biofilms. J Med Microbiol. 1998;47(3):253-256. doi: 10.1099/00222615-47-3-253

50. Baillie GS, Douglas LJ. Matrix polymers of Candida biofilms and their possible role in biofilm resistance to antifungal agents. J Antimicrob Chemother. 2000;46(3):397-403. doi:10.1093/jac/46.3.397

51. Richard ML, Nobile CJ, Bruno VM, Mitchell AP. Candida albicans biofilm-defective mutants. Eukaryot Cell. 2005;4(8):1493-1502. doi:10.1128/ec.4.8.14931502.2005

52. Ramage G, VandeWalle K, Lopez-Ribot JL, Wickes BL. The filamentation pathway controlled by the Efg1 regulator protein is required for normal biofilm formation and development in Candida albicans. FEMS Microbiol Lett. 
2002;214(1):95-100. doi:10.1111/j.1574-6968.2002. tb11330.x

53. Ramage G, Wickes BL, Lopez-Ribot JL. A seed and feed model for the formation of Candida albicans biofilms under flow conditions using an improved modified Robbins device. Rev Iberoam Micol. 2008;25(1):37-40. doi:10.1016/s1130-1406(08)70009-3

54. Chandra J, Mukherjee PK, Leidich SD, et al. Antifungal resistance of candidal biofilms formed on denture acrylic in vitro. J Dent Res. 2001;80(3):903-908. doi:1 $0.1177 / 00220345010800031101$

55. Chandra J, Kuhn DM, Mukherjee PK, Hoyer LL, McCormick T, Ghannoum MA. Biofilm formation by the fungal pathogen Candida albicans: development, architecture, and drug resistance. J Bacteriol. 2001;183(18):5385-5394. doi: 10.1128/ jb.183.18.5385-5394.2001

56. Al-Fattani MA, Douglas LJ. Penetration of Candida biofilms by antifungal agents. Antimicrob Agents Chemother. 2004;48(9):3291-3297. doi:10.1128/ aac.48.9.3291-3297.2004

57. Baillie GS, Douglas $L$. Effect of growth rate on resistance of Candida albicans biofilms to antifungal agents. Antimicrob Agents Chemother. 1998;42(8):1900-1905. doi: 10.1128/AAC.42.8.1900

58. Garcia-Sanchez S, Aubert S, Iraqui I, Janbon G, Ghigo JM, d'Enfert C. Candida albicans biofilms: a developmental state associated with specific and stable gene expression patterns. Eukaryot Cell. 2004;3(2):536-545. doi:10.1128/ec.3.2.536-545.2004

59. Nikawa H, Jin C, Makihira S, Egusa H, Hamada T, Kumagai $\mathrm{H}$. Biofilm formation of Candida albicans on the surfaces of deteriorated soft denture lining materials caused by denture cleansers in vitro. $J$ Oral Rehabil. 2003;30(3):243-250. doi:10.1046/j.13652842.2003.01024.x

60. Ramage G, Vande Walle K, Wickes BL, Lopez-Ribot JL. Standardized method for in vitro antifungal susceptibility testing of Candida albicans biofilms. Antimicrob Agents Chemother. 2001;45(9):2475-2479. doi:10.1128/aac.45.9.2475-2479.2001

61. Blankenship JR, Mitchell AP. How to build a biofilm: a fungal perspective. Curr Opin Microbiol. 2006;9(6):588594. doi:10.1016/j.mib.2006.10.003

62. Ramage G, Vandewalle K, Wickes BL, Lopez-Ribot $\mathrm{JL}$. Characteristics of biofilm formation by Candida albicans. Rev Iberoam Micol. 2001;18(4):163-170.

63. Zhao X, Daniels KJ, Oh SH, et al. Candida albicans Als $3 p$ is required for wild-type biofilm formation on silicone elastomer surfaces. Microbiology (Reading). 2006;152(Pt 8):2287-99. doi:10.1099/mic.0.28959-0

64. Li F, Svarovsky MJ, Karlsson AJ, et al. Eap1p, an adhesin that mediates Candida albicans biofilm formation in vitro and in vivo. Eukaryot Cell. 2007;6(6):931-939. doi:10.1128/ec.00049-07

65. Mukaremera L, Lee KK, Mora-Montes HM, Gow NAR. Candida albicans Yeast, Pseudohyphal, and Hyphal Morphogenesis Differentially Affects Immune Recognition. Front Immunol. 2017;8:629. doi:10.3389/ fimmu.2017.00629

66. Nett JE, Sanchez H, Cain MT, Andes DR. Genetic basis of Candida biofilm resistance due to drug-sequestering matrix glucan. J Infect Dis. 2010;202(1):171-175. doi:10.1086/651200

67. Bonhomme J, Chauvel M, Goyard S, Roux P, Rossignol T, d'Enfert C. Contribution of the glycolytic flux and hypoxia adaptation to efficient biofilm formation by Candida albicans. Mol Microbiol. 2011;80(4):9951013. doi: 10.1111/j.1365-2958.2011.07626.x

68. Uppuluri P, Chaturvedi AK, Srinivasan A, et al. Dispersion as an important step in the Candida albicans biofilm developmental cycle. PLOS Pathog. 2010;6(3):e1000828. doi:10.1371/journal. ppat.1000828

69. Finkel JS, Mitchell AP. Genetic control of Candida albicans biofilm development. Nat Rev Microbiol. 2011;9(2):109-118. doi:10.1038/nrmicro2475

70. Nobile CJ, Mitchell AP. Genetics and genomics of Candida albicans biofilm formation. Cell Microbiol. 2006;8(9):1382-1391. doi:10.1111/j.14625822.2006.00761.x

71. Fanning $S, X u$ W, Solis N, Woolford CA, Filler SG, Mitchell AP. Divergent targets of Candida albicans biofilm regulator Bcr1 in vitro and in vivo. Eukaryot Cell. 2012;11(7):896-904. doi:10.1128/ec.00103-12

72. Seth AK, Geringer MR, Hong SJ, Leung KP, Mustoe TA, Galiano RD. In vivo modeling of biofilm-infected wounds: a review. J Surg Res. 2012;178(1):330-338. doi:10.1016/j.jss.2012.06.048

73. Kauffman CA, Vazquez JA, Sobel JD, et al. Prospective multicenter surveillance study of funguria in hospitalized patients. Clin Infect Dis. 2000;30(1): 14-18. doi:10.1086/313583

74. Wenastein RA, Lundstrom T, Sobel J. Nosocomial candiduria: a review. Clin Infect Dis. 2001;32(11):16021607. doi:10.1086/320531

75. Damman CJ, Miller SI, Surawicz CM, Zisman TL. The microbiome and inflammatory bowel disease: is there a therapeutic role for fecal microbiota transplantation? Am J Gastroenterol. 2012;107(10):1452-1459. doi:10.1038/ajg.2012.93

76. Cugini C, Calfee MW, Farrow JM III, Morales DK, Pesci EC, Hogan DA. Farnesol, a common sesquiterpene, inhibits PQS production in Pseudomonas aeruginosa. Mol Microbiol. 2007;65(4):896-906. doi:10.1111/ j.1365-2958.2007.05840.x

77. Buijssen KJ, van der Laan BF, van der Mei HC, et al. Composition and architecture of biofilms on used voice prostheses. Head Neck. 2012;34(6):863-871. doi:10.1002/hed.21833

78. Ell SR. Candida'the cancer of silastic'. J Laryngol Otol. 1996;110(3):240-242. doi: 10.1017/ S0022215100133304

79. Jakubovics NS. Talk of the town: interspecies communication in oral biofilms. Mol Oral Microbiol. 2010;25(1):4-14. doi:10.1111/j.20411014.2009.00563.x

80. Uy R, Wold F. Posttranslational covalent modification of proteins. Science. 1977;198(4320):890-896. doi:10.1126/science.337487

81. Green KD, Garneau-Tsodikova S. Posttranslational Modification of Proteins. 2010;433-468. doi: 10.1016/ B978-008045382-8.00662-6

82. Chen B, Sun Y, Niu J, Jarugumilli GK, Wu X. Protein 
Lipidation in Cell Signaling and Diseases: Function, Regulation, and Therapeutic Opportunities. Cell Chem Biol. 2018;25(7):817-831. doi:10.1016/j. chembiol.2018.05.003

83. Wright $\mathrm{MH}$, Heal WP, Mann DJ, Tate EW. Protein myristoylation in health and disease. $J$ Chem Biol. 2010;3(1):19-35. doi:10.1007/s12154-009-0032-8

84. Aicart-Ramos C, Valero RA, Rodriguez-Crespo I. Protein palmitoylation and subcellular trafficking. Biochim Biophys Acta. 2011;1808(12):2981-2994. doi:10.1016/j.bbamem.2011.07.009

85. Chang S-C, Magee Al. Acyltransferases for secreted signalling proteins. Mol Membr Biol. 2009;26(12):104-113. doi: 10.1080/09687680802706432

86. Magee Al, Courtneidge SA. Two classes of fatty acid acylated proteins exist in eukaryotic cells. EMBO J. 1985;4(5):1137-1144.

87. Mcllhinney RA, Pelly SJ, Chadwick JK, Cowley GP. Studies on the attachment of myristic and palmitic acid to cell proteins in human squamous carcinoma cell lines: evidence for two pathways. EMBO J. 1985;4(5):1145-1152. doi: 10.1002/j.1460-2075.1985. tb03752.x

88. Devadas B, Freeman SK, Zupec ME, et al. Design and synthesis of novel imidazole-substituted dipeptide amides as potent and selective inhibitors of Candida albicans myristoylCoA:protein $\mathrm{N}$-myristoyltransferase and identification of related tripeptide inhibitors with mechanism-based antifungal activity. I Med Chem. 1997;40(16):2609-2625. doi:10.1021/jm970094w

89. Rocque WJ, McWherter CA, Wood DC, Gordon JI. A comparative analysis of the kinetic mechanism and peptide substrate specificity of human and Saccharomyces cerevisiae myristoyl-CoA:protein Nmyristoyltransferase. J Biol Chem. 1993;268(14):99649971. doi: 10.1016/S0021-9258(18)82159-7

90. Vetting MW, LP SdC, Yu M, et al. Structure and functions of the GNAT superfamily of acetyltransferases. Arch Biochem Biophys. 2005;433(1):212-226. doi:10.1016/j. abb.2004.09.003

91. Sogabe S, Masubuchi M, Sakata K, et al. Crystal structures of Candida albicans N-myristoyltransferase with two distinct inhibitors. Chem Biol. 2002;9(10):1119-1128. doi: 10.1016/s1074- 5521(02)00240-5

92. Rudnick DA, McWherter CA, Rocque WJ, Lennon PJ, Getman DP, Gordon JI. Kinetic and structural evidence for a sequential ordered $\mathrm{Bi} \mathrm{Bi}$ mechanism of catalysis by Saccharomyces cerevisiae myristoyl-CoA:protein Nmyristoyltransferase. J Biol Chem. 1991;266(15):97329739. doi: 10.1016/S0021-9258(18)92882-6

93. Ducker CE, Upson JJ, French KJ, Smith CD. Two Nmyristoyltransferase isozymes play unique roles in protein myristoylation, proliferation, and apoptosis. Mol Cancer Res. 2005;3(8):463-476. doi:10.1158/15417786.mcr-05-0037

94. Zha J, Weiler S, Oh KJ, Wei MC, Korsmeyer SJ. Posttranslational N-myristoylation of BID as a molecular switch for targeting mitochondria and apoptosis. Science. 2000;290(5497):1761-1765. doi:10.1126/science.290.5497.1761

95. Peitzsch RM, McLaughlin S. Binding of acylated peptides and fatty acids to phospholipid vesicles: pertinence to myristoylated proteins. Biochemistry. 1993;32(39):10436-10443. doi:10.1021/bi00090a020

96. Gordon JI, Duronio RJ, Rudnick DA, Adams SP, Gokel GW. Protein N-myristoylation. J Biol Chem. 1991;266(14):8647-8650. doi: 10.1016/S00219258(18)31490-X

97. Farazi TA, Waksman G, Gordon Jl. The biology and enzymology of protein N-myristoylation. J Biol Chem. 2001;276(43):39501-39504. doi:10.1074/jbc. R100042200

98. Lodge JK, Johnson RL, Weinberg RA, Gordon JI. Comparison of myristoyl-CoA:protein Nmyristoyltransferases from three pathogenic fungi: Cryptococcus neoformans, Histoplasma capsulatum, and Candida albicans. J Biol Chem. 1994;269(4):29963009. doi: 10.1016/S0021-9258(17)42038-2

99. Nakayama H, Mio T, Nagahashi S, Kokado M, Arisawa M, Aoki Y. Tetracycline-regulatable system to tightly control gene expression in the pathogenic fungus Candida albicans. Infect Immun. 2000;68(12):67126719. doi:10.1128/iai.68.12.6712-6719.2000

100. Weinberg RA, McWherter CA, Freeman SK, Wood DC, Gordon JI, Lee SC. Genetic studies reveal that myristoylCoA:protein $\mathrm{N}$-myristoyltransferase is an essential enzyme in Candida albicans. Mol Microbiol. 1995;16(2):241-250. doi: 10.1111/j.1365-2958.1995. tb02296.x

101. Masubuchi M, Kawasaki K, Ebiike H, et al. Design and synthesis of novel benzofurans as a new class of antifungal agents targeting fungal Nmyristoyltransferase. Part 1. Bioorg Med Chem Lett. 2001;11(14):1833-1837. doi:10.1016/s0960894x(01)00319-5

102. Ebiike $\mathrm{H}$, Masubuchi M, Liu P, et al. Design and synthesis of novel benzofurans as a new class of antifungal agents targeting fungal $\mathrm{N}$ - myristoyltransferase. Part 2. Bioorg Med Chem Lett. 2002;12(4):607-610. doi: 10.1016/s0960- 894x(01)00808-3

103. Kawasaki K, Masubuchi M, Morikami K, et al. Design and synthesis of novel benzofurans as a new class of antifungal agents targeting fungal $\mathrm{N}$ myristoyltransferase. Part 3. Bioorg Med Chem Lett. 2003;13(1):87-91. doi:10.1016/s0960- 894x(02)008442

104. Ebara S, Naito H, Nakazawa K, Ishii F, Nakamura M. FTR1335 is a novel synthetic inhibitor of Candida albicans $\mathrm{N}$-myristoyltransferase with fungicidal activity. Biol Pharm Bull. 2005;28(4):591-595. doi:10.1248/bpb.28.591

105. Paige LA, Zheng GQ, DeFrees SA, Cassady JM, Geahlen RL. Metabolic activation of 2-substituted derivatives of myristic acid to form potent inhibitors of myristoyl CoA:protein N-myristoyltransferase. Biochemistry. 1990;29(46):10566-10573. doi:10.1021/bi00498a021

106. Parang K, Knaus EE, Wiebe LI, Sardari S, Daneshtalab $M$, Csizmadia F. Synthesis and antifungal activities of myristic acid analogs. Archiv der Pharmazie. 1996;329(11):475-482. doi:10.1002/ ardp.19963291102

107. Devadas B, Zupec ME, Freeman SK, et al. Design and syntheses of potent and selective dipeptide inhibitors of Candida albicans myristoyl-CoA:protein N- 
myristoyltransferase. J Med Chem. 1995;38(11):18371840. doi:10.1021/jm00011a001

108. Pathare SS, Bhansali SG, Mahadik KR, Kulkarni VM. Pharmacophore modeling and atom-based 3d-qsar studies of antifungal benzofurans. Int J Pharm Pharm Sci. 2015;7(3):453-458.

109. Devadas B, Freeman SK, McWherter CA, et al. Novel biologically active nonpeptidic inhibitors of myristoyl CoA: protein N-myristoyltransferase. J Med Chem. 1998;41(6):996-1000.doi: 10.1021/jm980001q

110. Karki RG, Kulkarni VM. A feature based pharmacophore for Candida albicans MyristoylCoA: protein $\mathrm{N}$-myristoyltransferase inhibitors. Eur J Med Chem. 2001;36(2):147-163. doi:10.1016/s02235234(00)01202-2

111. Xu H, Hou Z, Liang Z, Guo MB, Su X, Guo C. Design, Synthesis and Antifungal Activity of Benzofuran and Its Analogues. Chin J Chem. 2019;37(12):1245-1250. doi: 10.1002/cjoc.201900304

112. Friesner RA, Banks JL, Murphy RB, et al. Glide: a new approach for rapid, accurate docking and scoring. 1. Method and assessment of docking accuracy. J Med Chem. 2004;47(7):1739-1749. doi: 10.1021/ jm0306430

113. Halgren TA, Murphy RB, Friesner RA, et al. Glide: a new approach for rapid, accurate docking and scoring. 2. Enrichment factors in database screening. J Med Chem. 2004;47(7):1750-1759. doi:10.1021/jm030644s

114. Friesner RA, Murphy RB, Repasky MP, et al. Extra precision glide: Docking and scoring incorporating a model of hydrophobic enclosure for protein- ligand complexes. J Med Chem. 2006;49(21):6177-6196. doi: 10.1021/jm051256o

115. Kellenberger E, Rodrigo J, Muller P, Rognan D. Comparative evaluation of eight docking tools for docking and virtual screening accuracy. Proteins. 2004;57(2):225-242. doi: 10.1002/prot.20149

116. Rashid M, Husain A, Shaharyar M, Mishra R, Hussain A, Afzal O. Design and synthesis of pyrimidine molecules endowed with thiazolidin-4-one as new anticancer agents. EurJ Med Chem. 2014;83:630-645. doi:10.1016/j.ejmech.2014.06.033

117. Hussain A, Verma CK. Molecular docking and in silico ADMET study reveals 3-(5-\{[4-(aminomethyl) piperidin-1-yl] methyl\}-1h-indol-2-yl)-1h-indazole-6carbonitrile as a potential inhibitor of cancer Osaka thyroid kinase. Biomed. Res. 2017;28(13):5805-5815.

118. Hussain A, Verma CK, Chouhan U. Identification of novel inhibitors against Cyclin Dependent Kinase 9/Cyclin T1 complex as: Anti cancer agent. Saudi J Biol Sci. 2017;24(6):1229-1242. doi: 10.1016/j. sjbs.2015.10.003

119. Hussain A, Verma CK. Recognition of New Inhibitor of CDK9/Cyclin T1 Complex as Persuasive Anticancer Agent. IJABR. 2016;7(2):654-668.

120. Morris GM, Goodsell DS, Halliday RS, et al. Automated docking using a Lamarckian genetic algorithm and an empirical binding free energy function. J Comput Chem. 1998;19(14):1639-1662. do i : $\quad 10.1002 /(\mathrm{S} \mid \mathrm{C}$ ।) 1096 987X(19981115)19:14<1639::AID-JCC10>3.0.CO;2-B

121. Ewing TJ, Makino S, Skillman AG, Kuntz ID. DOCK
4.0: search strategies for automated molecular docking of flexible molecule databases. J Comput Aided Mol Des.2001;15(5):411-428. doi:10.1023/a:1011115820450

122. Rarey M, Kramer B, Lengauer T, Klebe G. A fast flexible docking method using an incremental construction algorithm. J Mol Biol. 1996;261(3):470-489. doi: 10.1006/jmbi.1996.0477

123. Jones G, Willett P, Glen RC, Leach AR, Taylor R. Development and validation of a genetic algorithm for flexible docking. J Mol Biol. 1997;267(3):727-748. doi: 10.1006/jmbi.1996.0897

124. Jain AN. Surflex: fully automatic flexible molecular docking using a molecular similarity-based search engine. J Med Chem. 2003;46(4):499-511. doi: 10.1021/jm020406h

125. Abagyan R, Totrov M, Kuznetsov D. ICM-a new method for protein modeling and design: applications to docking and structure prediction from the distorted native conformation. J Comput Chem. 1994;15(5):488506. doi: 10.1002/jcc.540150503

126. Venkatachalam $\mathrm{CM}$, Jiang $\mathrm{X}$, Oldfield $\mathrm{T}$, Waldman $\mathrm{M}$. LigandFit: a novel method for the shape-directed rapid docking of ligands to protein active sites. J Mol Graph Model. 2003;21(4):289-307. doi: 10.1016/s10933263(02)00164-x

127. Zsoldos Z, Reid D, Simon A, Sadjad SB, Johnson AP. eHiTS: a new fast, exhaustive flexible ligand docking system. J Mol Graph Model. 2007;26(1):198-212. doi: 10.1016/j.jmgm.2006.06.002

128. Kitchen DB, Decornez H, Furr JR, Bajorath J. Docking and scoring in virtual screening for drug discovery: methods and applications. Nat Rev Drug Discov. 2004;3(11):935-949. doi: 10.1038/nrd1549

129. Wermuth C, Ganellin C, Lindberg P, Mitscher L. Glossary of terms used in medicinal chemistry (IUPAC Recommendations 1998). Pure Appl Chem. 1998;70(5):1129-1143. doi: 10.1351/ pac199870051129

130. Qing X, Lee XY, De Raeymaecker J, et al. Pharmacophore modeling: advances, limitations, and current utility in drug discovery. J Receptor Ligand Channel Res. 2014;7:81-92.10.2147/JRLCR.S46843

131. Pirhadi S, Shiri F, Ghasemi JB. Methods and applications of structure based pharmacophores in drug discovery. Curr Top Med Chem. 2013;13(9):1036-1047. doi: 10.2174/1568026611313090006

132. Hussain A, Verma CK. Ligand-and structure-based pharmacophore modeling, docking study reveals 2-[[4- [6-(isopropylamino) pyrimidin-4-yl]-1H-pyrrolo [2, 3- b] pyridin-6-yl] amino] ethanol as a potential anticancer agent of CDK9/cyclin T1 kinase. J Cancer Res Ther. 2019;15(5):1131-1140. doi: 10.4103/jcrt. JCRT_47_18

133. Vuorinen A, Engeli R, Meyer A, et al. Ligand-based pharmacophore modeling and virtual screening for the discovery of novel $17 \beta$-hydroxysteroid dehydrogenase 2 inhibitors. J Med Chem. 2014;57(14):5995-6007. doi: 10.1021/jm5004914

134. Hussain A, Verma CK. A Combination of Pharmacophore Modeling, Molecular Docking and Virtual Screening Study Reveals 3, 5, 7-Trihydroxy-2- 
(3, 4, 5-trihydroxyphenyl)-4H-Chromen-4-One as a Potential Anti-Cancer Agent of COT Kinase. Indian J Pharm Educ Res. 2018;52(4):699-706. doi: 10.5530/ ijper.52.4.81

135. Wolber G, Langer T. LigandScout: 3-D pharmacophores derived from protein-bound ligands and their use as virtual screening filters. J Chem Inf Model. 2005;45(1):160-169. doi: 10.1021/ci049885e

136. Ortuso F, Langer T, Alcaro S. GBPM: GRID-based pharmacophore model: concept and application studies to protein-protein recognition. Bioinformatics. 2006;22(12):1449-1455.doi: 10.1093/bioinformatics/ btl115

137. Chen J, Lai L. Pocket v. 2: further developments on receptor-based pharmacophore modeling. J Chem Inf Model. 2006;46(6):2684-2691. doi: 10.1021/ci600246s

138. Patel Y, Gillet VJ, Bravi G, Leach AR. A comparison of the pharmacophore identification programs: Catalyst, DISCO and GASP. J Comput Aided Mol Des. 2002;16(89):653-681. doi: 10.1023/a:1021954728347

139. Jansen JM, Copinga S, Gruppen G, Molinari EJ, Dubocovich ML, Grol CJ. The high affinity melatonin binding site probed with conformationally restricted ligands-I. Pharmacophore and minireceptor models. Bioorg Med Chem. 1996;4(8):1321-1332. doi: 10.1016/0968-0896(96)00113-7

140. Richmond NJ, Abrams CA, Wolohan PR, Abrahamian E, Willett P, Clark RD. GALAHAD: 1. Pharmacophore identification by hypermolecular alignment of ligands in 3D. J Comput Aided Mol Des. 2006;20(9):567-587. doi: 10.1007/s10822-006-9082-y

141. Tian Y-S, Kawashita N, Arai Y, Okamoto K, Takagi T. Pharmacophore Modeling and Molecular Docking Studies of potential inhibitors to E6 PBM-PDZ from Human Papilloma Virus (HPV). Bioinformation. 2015;11(8):401-6. doi: 10.6026/97320630011401

142. Holliday JD, Willett P. Using a genetic algorithm to identify common structural features in sets of ligands. J Mol Graph Model. 1997;15(4):221-232. doi: 10.1016/ s1093-3263(97)00080-6

143. Guner O, Clement O, Kurogi Y. Pharmacophore modeling and three dimensional database searching for drug design using catalyst: recent advances. Curr Med Chem. 2004;11(22):2991-3005. doi: 10.2174/0929867043364036

144. Schuster D, Laggner C, Steindl TM, Palusczak A, Hartmann RW, Langer T. Pharmacophore modeling and in silico screening for new P450 19 (aromatase) inhibitors. J Chem Inf Model. 2006;46(3):1301-1311. doi:10.1021/ci050237k

145. Hariprasad V, Kulkarni VM. A proposed common spatial pharmacophore and the corresponding active conformations of some peptide leukotriene receptor antagonists. J Comput Aided Mol Des. 1996;10(4):284292. doi: $10.1007 /$ BF00124498

146. Dolata D, Parrill A, Walters W. CLEW: the generation of pharmacophore hypotheses through machine learning. SAR QSAR Environ Res. 1998;9(1-2):53-81. doi: 10.1080/10629369808039149

147. Handschuh S, Wagener M, Gasteiger J. Superposition of three-dimensional chemical structures allowing for conformational flexibility by a hybrid method. J Chem
Inf Comput Sci. 1998;38(2):220-232. doi: 10.1021/ ci970438r

148. Dixon SL, Smondyrev AM, Rao SN. PHASE: a novel approach to pharmacophore modeling and 3D database searching. Chem Biol Drug Des. 2006;67(5):370-372. doi: 10.1111/j.1747-0285.2006.00384.x

149. Dixon SL, Smondyrev AM, Knoll EH, Rao SN, Shaw DE, Friesner RA. PHASE: a new engine for pharmacophore perception, 3D QSAR model development, and 3D database screening: 1 . Methodology and preliminary results. J Comput Aided Mol Des. 2006;20(10-11):647671. doi: 10.1007/s10822-006-9087-6

150. Schneidman-Duhovny D, Dror O, Inbar Y, Nussinov $\mathrm{R}$, Wolfson HJ. PharmaGist: a webserver for ligandbased pharmacophore detection. Nucleic Acids Res. 2008;36(suppl_2):W223-W228. doi: 10.1093/nar/ gkn187

151. Prasad NK, Kanakaveti V, Eadlapalli S, Vadde R, Meetei AP, Vindal V. Ligand-based pharmacophore modeling and virtual screening of RAD9 inhibitors. J Chem. 2013;2013:679459. doi:10.1155/2013/679459

152. Schneider G, Neidhart W, Giller T, Schmid G. Scaffold-Hopping" by Topological Pharmacophore Search: A Contribution to Virtual Screening. Angew Chem Int Ed Engl. 1999;38(19):2894- 2896. doi: $10.1002 /(\mathrm{SICI}) 1521-3773(19991004)$ 38:19<2894::AID-ANIE2894>3.0.CO;2-F

153. Sneader W. Drug prototypes and their exploitation. Eur J Med Chem. 1997;32(1):91. doi: 10.1016/S02235234(97)84366-8

154. Cramer RD, Jilek RJ, Guessregen S, Clark SJ, Wendt B, Clark RD. "Lead hopping". Validation of topomer similarity as a superior predictor of similar biological activities. J Med Chem. 2004;47(27):6777-6791. doi:10.1021/jm049501b

155. Martin YC, Muchmore S. Beyond QSAR: lead hopping to different structures. QSAR Comb Sci. 2009;28(8):797801. doi: 10.1002/qsar.200810176

156. Schneider G, Schneider P, Renner S. Scaffoldhopping: how far can you jump? QSAR Comb Sci. 2006;25(12):1162-1171. doi: 10.1002/qsar.200610091

157. Bohm HJ, Flohr A, Stahl M. Scaffold hopping. Drug Discov Today Technol. 2004;1(3):217-224. doi:10.1016/j.ddtec.2004.10.009

158. Brown N, Jacoby E. Onscaffolds and hopping in medicinal chemistry. Mini Rev Med Chem. 2006;6(11):1217-29. doi:10.2174/138955706778742768

159. Mauser H, Guba W. Recent developments in de novo design and scaffold hopping. Curr Opin Drug Discov Devel. 2008;11(3):365-374.

160. Cramer RD, Poss MA, Hermsmeier MA, Caulfield TJ, Kowala MC, Valentine MT. Prospective identification of biologically active structures by topomer shape similarity searching. J Med Chem. 1999;42(19):39193933. doi:10.1021/jm990159q

161. Johnson MA, Maggiora GM. Concepts and applications of molecular similarity. J Comput Chem. 1990;13(4):539-540. doi: 10.1002/jcc.540130415

162. Bohm HJ, Klebe G. What can we learn from molecular recognition in protein-ligand complexes for the design of new drugs? Angew Chem Int Ed Engl. 1996;35(22):2588-2614.doi: 10.1002/anie.199625881 
163. Good AC, Mason JS. Three-dimensional structure database searches. Rev Comput Chem. 1996:67-117. doi: 10.1002/9780470125847.ch2

164. Van Drie JH. Strategies for the determination of pharmacophoric 3D database queries. J Comput Aided Mol Des. 1997;11(1):39-52. doi: 10.1023/a:1008019326401

165. Kaminski JJ, Rane D, Snow ME, et al. Identification of novel farnesyl protein transferase inhibitors using three- dimensional database searching methods. J Med Chem. 1997;40(25):4103-4112. doi: 10.1021/ jm970291v

166. Barreca ML, Gitto R, Quartarone S, De Luca L, De Sarro G, Chimirri A. Pharmacophore modeling as an efficient tool in the discovery of novel noncompetitive AMPA receptor antagonists. J Chem Inf Comput Sci. 2003;43(2):651-655. doi: 10.1021/ci025625q

167. Lauri G, Bartlett PA. CAVEAT: a program to facilitate the design of organic molecules. J Comput Aided Mol Des. 1994;8(1):51-66. doi:10.1007/BF00124349

168. Pierce AC, Rao G, Bemis GW. BREED: Generating novel inhibitors through hybridization of known ligands. Application to CDK2, p38, and HIV protease. J Med Chem. 2004;47(11):2768- 2775. doi: 10.1021/ jm030543u

169. Lewell $X Q$, Jones $A C$, Bruce $C L$, et al. Drug rings database with web interface. A tool for identifying alternative chemical rings in lead discovery programs. J Med Chem. 2003;46(15):3257- 3274.doi: 10.1021/ jm0300429

170. Rarey M, Dixon JS. Feature trees: a new molecular similarity measure based on tree matching. J Comput Aided Mol Des. 1998;12(5):471-490. doi: 10.1023/a:1008068904628

171. Sheridan RP, Kearsley SK. Why do we need so many chemical similarity search methods? Drug Discov Today. 2002;7(17):903-911. doi: 10.1016/s13596446(02)02411-x

172. Lengauer T, Lemmen C, Rarey M, Zimmermann M. Novel technologies for virtual screening. Drug Discov Today. 2004;9(1):27-34. doi: 10.1016/S13596446(04)02939-3

173. Geppert H, Vogt M, Bajorath J. Current trends in ligandbased virtual screening: molecular representations, data mining methods, new application areas, and performance evaluation. J Chem Inf Model. 2010;50(2):205-216. doi:10.1021/ci900419k

174. Schneider P, Tanrikulu Y, Schneider G. Selforganizing maps in drug discovery: compound library design, scaffold-hopping, repurposing. Curr Med Chem. 2009;16(3):258-266. doi: $10.2174 / 092986709787002655$

175. Yuan S, Chan HS, Hu Z. Implementing WebGL and HTML5 in macromolecular visualization and modern computer-aided drug design. Trends Biotechnol. 2017;35(6):559-571. doi: 10.1016/j. tibtech.2017.03.009

176. Floresta G, Rescifina A, Marrazzo A, et al. Hyphenated 3D-QSAR statistical model-scaffold hopping analysis for the identification of potentially potent and selective sigma-2 receptor ligands. Eur J Med Chem. 2017;139:884-891. doi: 10.1016/j.ejmech.2017.08.053
177. Wang X-J, Zhang J, Wang S-Q, Xu W-R, Cheng X-C, Wang $\mathrm{R}-\mathrm{L}$. Identification of novel multitargeted PPAR $\alpha / \mathrm{V} / \delta$ pan agonists by core hopping of rosiglitazone. Drug Des Devel Ther. 2014;8:2255-2262. doi: 10.2147/DDDT. S70383

178. Quintus F, Sperandio O, Grynberg J, Petitjean M, Tuffery $P$. Ligand scaffold hopping combining 3D maximal substructure search and molecular similarity. $B M C$ Bioinformatics. 2009;10(1):245. doi: 10.1186/14712105-10-245

179. Douguet D. e-LEA3D: a computational-aided drug design web server. Nucleic Acids Res. 2010;38(Web Server issue):W615-21. doi:10.1093/nar/gkq322

180. Gong J, Cai C, Liu X, et al. ChemMapper: a versatile web server for exploring pharmacology and chemical structure association based on molecular 3D similarity method. Bioinformatics. 2013;29(14):1827-1829. doi: 10.1093/bioinformatics/btt270

181. Ahlstrom MM, Ridderstrom M, Luthman K, Zamora I. Virtual screening and scaffold hopping based on GRID molecular interaction fields. J Chem Inf Model. 2005;45(5):1313-1323. doi:10.1021/ci049626p

182. Gurusamy M, Abdul JF. Lead Optimization Studies Towards Finding NS2B/NS3 Protease Target-specific Inhibitors as Potential Anti-dengue Drug-like Compounds. Curr Drug Discov Technol. 2019;16(3):307314. doi: 10.2174/1570163815666180709155131

183. Maass P, Schulz-Gasch T, Stahl M, Rarey M. Recore: a fast and versatile method for scaffold hopping based on small molecule crystal structure conformations. J Chem Inf Model. 2007;47(2):390-399. doi:10.1021/ ci060094h

184. Wassermann AM, Lounkine E, Urban L, et al. A screening pattern recognition method finds new and divergent targets for drugs and natural products. ACS Chem Biol. 2014;9(7):1622-1631. doi:10.1021/ cb5001839

185. Beno BR, Langley DR. MORPH: a new tool for ligand design. J Chem Inf Model. 2010;50(6):1159-1164. doi: 10.1021/ci9004964

186. McCammon JA, Gelin BR, Karplus M. Dynamics of folded proteins. Nature. 1977;267(5612):585-590. doi: 10.1038/267585a0

187. Allen F, Almasi G, Andreoni W, et al. Blue Gene: A vision for protein science using a petaflop supercomputer. IBM Syst J. 2001;40(2):310-327. doi: 10.1147/ sj.402.0310

188. Hess B, Kutzner C, Van Der Spoel D, Lindahl E. GROMACS 4: algorithms for highly efficient, loadbalanced, and scalable molecular simulation. J Chem Theory Comput. 2008;4(3):435-447. doi: 10.1021/ ct700301q

189. Shaw DE, Deneroff MM, Dror RO, et al. Anton, a special-purpose machine for molecular dynamics simulation. Commun ACM. 2008;51(7):91-97. doi: 10.1145/1364782.1364802

190. Liu W, Schmidt B, Voss G, Muller-Wittig W. Accelerating molecular dynamics simulations using Graphics Processing Units with CUDA. Comput Phys Commun. 2008;179(9):634-641. doi: 10.1016/j.cpc.2008.05.008

191. Harvey M, De Fabritiis G. A survey of computational molecular science using graphics processing units. 
Wiley Interdiscip Rev Comput Mol Sci. 2012;2(5):734742. doi:10.1002/wcms.1101

192. Monticelli L, Tieleman DP. Force fields for classical molecular dynamics. Biomolecular simulations. Springer. 2013;924:197-213. doi: 10.1007/978-162703-017-5_8

193. Case DA, Cheatham III TE, Darden T, et al. The Amber biomolecular simulation programs. I Comput Chem. 2005;26(16):1668-1688. doi:10.1002/jcc.20290

194. Brooks BR, Brooks III CL, Mackerell Jr AD, et al. CHARMM: the biomolecular simulation program. $J$ Comput Chem. 2009;30(10):1545-1614. doi: 10.1002/ jcc. 21287

195. Nelson MT, Humphrey W, Gursoy A, et al. NAMD: a parallel, object-oriented molecular dynamics program.
The International Journal of Supercomputer Applications and High Performance Computing. 1996;10(4):251268. doi: $10.1177 / 109434209601000401$

196. Chow E, Rendleman CA, Bowers KJ, et al. Desmond performance on a cluster of multicore processors. $D E$ Shaw Research Technical Report DESRES/TR--2008- 01. 2008.

197. Yan T, Burnham CJ, Del Popolo MG, Voth GA. Molecular dynamics simulation of ionic liquids: The effect of electronic polarizability. J Phys Chem B. 2004;108(32):11877-11881. doi: 10.1021/jp047619y

198. Limbach H-J, Arnold A, Mann BA, Holm C. ESPResSoan extensible simulation package for research on soft matter systems. Comput Phys Commun. 2006;174(9):704-727. doi:10.1016/j.cpc.2005.10.005 